Max-Planck-Institut für demografische Forschung

Max Planck Institute for Demographic Research

Konrad-Zuse-Strasse $1 \cdot$ D-18057 Rostock · GERMANY

Tel +49 (0) 3812081 - 0; Fax +49 (0) 3812081 - 202;

http://www.demogr.mpg.de

MPIDR WORKING PAPER WP 2012-013

FEBRUARY 2012 (REVISED NOVEMBER 2012)

\title{
Happiness: Before and After the Kids
}

Mikko Myrskylä (myrskyla@demogr.mpg.de)

Rachel Margolis

(C) Copyright is held by the authors.

Working papers of the Max Planck Institute for Demographic Research receive only limited review. Views or opinions expressed in working papers are attributable to the authors and do not necessarily reflect those of the Institute. 


\title{
Happiness: Before and After the Kids
}

Mikko Myrskylä [1]

Rachel Margolis [2]

\begin{abstract}
Understanding how having children influences the parents' subjective well-being (“happiness”) has great potential to explain fertility behavior. Most prior research on this topic is limited in that it uses cross-sectional data or has not considered modifying factors. We study parental happiness trajectories before and after the birth of a child using large British and German longitudinal data sets. We account for unobserved parental characteristics using fixed effects models and study how sociodemographic factors modify the parental happiness trajectories. Overall, we find that happiness increases in the years around the birth of the first child, then decreases to before-child levels. Sociodemographic factors strongly modify this pattern. Those who have children at older ages and those with higher socioeconomic resources have more positive and lasting happiness response to a first birth than younger or less educated parents. We also find that although the first two children increase happiness, the third does not. The results are similar in Britain and Germany and suggest that up to two, children increase happiness, and mostly among those who postpone childbearing. This pattern, which is consistent with the behavior emerging during the second demographic transition, provides new insights into the factors behind low and late fertility.
\end{abstract}

Acknowledgements: We are grateful for comments from Sam Preston, Bill Avison, Elizabeth Gregory, Josh Goldstein, Carl Schmertmann, Debby Carr, and Michaela Kreyenfeld.

Funding: This research has been supported by the Max Planck Institute for Demographic Research, University of Western Ontario, and University of Pennsylvania.

Key words: Fertility, Well-being, Life course, Parenthood

[1] Corresponding author. Max Planck Institute for Demographic Research, Konrad-Zuse-Str. 1, 18057 Rostock, Germany. Phone+49 (0)381 2081-118, Fax +49 (0)381 2081-418, Email myrskyla@demogr.mpg.de

[2] Department of Sociology, University of Western Ontario, Social Science Center \#5326, London Ontario N6A 5C2, Canada

Email: rachel.margolis@uwo.ca 


\section{Introduction}

In the early 1990s, fertility levels reached a new low in much of the developed world, triggering an intense policy debate about what to do about low fertility and the myriad problems it causes, such as population aging. Much of low period fertility has been due to the postponement of births and stopping at one child, rather than high levels of childlessness (Sobotka 2004), therefore policy discussion has focused on the reasons behind postponement and why many stop at one child when most say they want two (Adema and Whiteford 2007; European Commission 2006). Part of the desired-actual fertility gap is explained by measurement, as desired fertility is a cohort concept but fertility behavior is often measured on a period basis. However, even if these differences are accounted for, the gap remains, averaging 0.34 children per woman in the European Union (Sobotka and Lutz 2011).

Much research attempting to explain low and late fertility focuses on the rise of individualistic values and the incompatibility of family and career desires, particularly for women (Adsera 2004; Feyrer et al. 2008; Gauthier 2007; McDonald 2000; van de Kaa et al. 2003). Subjective well-being of parents has received considerably less attention. We analyze how children influence parental well-being, which is important for two reasons. First, at a time when having children is a matter of choice for most people in the developed world and the economic costs associated with children are large, the subjective well-being of parents has enormous potential to explain why most have one or two children and why people postpone childbearing (Hobcraft 2006). Second, parental well-being is important for adult health and child outcomes (Turney 2011). Understanding how childbearing, an event most people experience, influences parental well-being is essential for understanding population-level fertility behavior and individual-level outcomes. 
Recent work documents that parity is significantly associated with parental well-being, and that the relationship between the number of children and well-being varies with age, individual characteristics, and institutional context (Baranowska and Matysiak 2011; Clark et al. 2008; Kohler et al. 2005; Margolis and Myrskylä 2011; Nomaguchi and Brown 2011). Most prior research on subjective well-being and fertility relies on cross-sectional data. However, when the question is how children influence parental well-being, it is crucial to account for the level of well-being before children, instead of comparing those with children to those without because parents and the childless may differ in many respects beyond observable factors. Longitudinal data allow analyzing an individual's well-being over time, thus overcoming this problem. Existing longitudinal research, however, has only looked at average effects of children on well-being, lumping together first, second, and all higher order births, ignored potential differences by parity and other sociodemographic characteristics, or has not considered mediators of childbearing on happiness, such as labor force participation and health. We hypothesize, and show in this paper, that breaking down the analysis by parity and sociodemographic characteristics is critical.

We chart changes in well-being over the adult life course before and after a birth using panel data, examine patterns by population subgroups, and examine how parental well-being changes when children grow up. We also test whether the set-point theory of happiness holds for fertility. Set-point theory states that after short-term fluctuations due to life events, happiness converges back to one’s individual set point (Brickman and Campbell 1971; Larsen 2000; Lykken and Tellegren 1996). Our results show that for the population as a whole, post-birth happiness converges to initial pre-birth levels. However, we find important variation in both the short- and long-term effects of the birth on parental well-being by parity and sociodemographic 
characteristics. These findings provide new insights into fertility behavior and shed light on the determinants of parental well-being, which in itself is an important outcome.

\section{Trajectories of Parental Well-being}

Previous cross-sectional research has examined whether parents are more or less happy than those without children and highlights the importance of stage in the life cycle in determining the well-being of parents relative to non-parents. For example, young parents show higher levels of distress than non-parents (Cleary and Mechanic 1983; Gore and Mangione 1983; Lovell-Troy 1983; Margolis and Myrskyla 2011; McLanahan and Adams 1987). At older ages, there is no difference in well-being by parental status (Connidis and McMullin 1993; Koropeckyj-Cox et al. 2007; Rempel 1985; Ross and Huber 1985), or parents have even higher levels of well-being than the childless (Margolis and Myrskyla 2011). These cross-sectional analyses provide important insights into the fertility-happiness association, but have limited power in informing us about causal relationships. For example, cross-sectional analyses may be biased by factors such as personality, genetic factors, or other unobserved or difficult-to-measure characteristics such as orientation towards career versus family which may be associated with both the fertility behavior and subjective well-being (Alvergne et al. 2010; de Neve 2011; Rogers et al. 2001)

Several studies have examined parental well-being trajectories using panel data (Angeles 2010; Baranowska and Matysiak 2011; Clark et al. 2008; Clark and Georgellis 2010; Frijters et al. 2011). Clark and colleagues (2008) analyzed the longitudinal pattern in happiness before and after major life events, one of which was the birth of a child. Their approach controls for unobserved fixed characteristics, such as personality and selection into parenthood. Using the German Socioeconomic Panel, they find that within a ten-year window with the birth of a child 
in the middle, the happiness of both men and women tends to increase before and up to a birth, and then decreases to the pre-birth levels. However, the focus of the study by Clark et al. (2008) was anticipation and adaptation to life events, and childbearing was only one of the many life events considered. Consequently, childbearing received only cursory treatment, and the study did not consider long-term trajectories, or how the pattern may differ by parity or other parental characteristics.

Frijters et al. (2011) analyzed Australian panel data and also found that although happiness increases around birth, happiness returns to the baseline level in less than two years. Clark and Georgellis (2010) and Angeles (2010) have used the British Household Panel Survey to analyze whether the happiness of new parents adapts to their new circumstances. Similar to Clark et al. (2008), each of these studies focuses on adaptation, and does not consider long-run trajectories or differences by birth order or SES.

We build on this work to examine how the trajectory of parental well-being around the birth of a child might depend on parity and other sociodemographic characteristics, how the pattern changes in the long-run when children grow up, analyze the role of mediating factors, and compare the happiness trajectories of parents across contexts.

\section{Subgroup Differences in Parental Happiness Trajectories}

The happiness trajectory of parents may vary by age at parenthood, socioeconomic status, and gender. Our hypotheses about age at first birth are based on several quantitative and qualitative studies which suggest that women with more social and economic resources have less steep postbirth dips in life satisfaction than those with fewer resources. For example, parents with lower 
levels of education and income have markedly higher rates of post-birth depression (Avison and Davies 2005; O'Hara 2009).

Increasing educational and job opportunities for women have in part led to the postponement of childbirth. Research on older mothers suggests that women who postpone childbearing are more "ready” and less stressed by having children (Gregory 2007). Gregory argues that older mothers are more ready because they have higher status at work which allows greater financial flexibility, options for childcare, and more social capital which ease the transition to parenthood. Because it is not clear whether being "ready" is captured by chronological age of the parents, educational attainment, or income, we analyze all of them.

Not all evidence points to higher education and income being associated with more positive well-being trajectories for parents. The stress about "perfect" mothering may have negative effects on high SES mothers' well-being (MacDonald 2011). Moreover, those with low SES may have different expectations for how childbearing affects the lives of parents (Edin and Kefalas 2005; Nomaguchi and Brown 2011) or may have larger kin networks, though they do not necessarily turn into more instrumental support (Harknett and Knab 2007). Higher pre-birth education and income may also imply higher opportunity costs of childbearing.

Some evidence suggests that post-birth dips in life satisfaction will be stronger for women than men (Clark et al. 2008). This accords with much research in sociology, which documents that women are more socially isolated after childbirth as they often take a leave from the labor force and are most often the primary caregiver, particularly when the child is young and most demanding (Della Giusta et al. 2011; Simon 1992). 


\section{Parity}

Most prior research averages the happiness response of parents to the birth of a child over all parities, or alternatively focus only on the first birth (Clark et al. 2008; Clark and Georgellis 2010; Frijters et al. 2011). Kohler et al. (2005) is an exception and they find that first births have a positive effect on parental happiness, but not higher order births. Although parity may be an important modifier of the effect of a birth on happiness, the direction of modification is ambiguous. If birth is a positive life event, the happiness response to having a child may be strongest when the event is experienced for the first time, and weaker for further births. Moreover, higher parity children might increase happiness less than the first birth because of resource dilution. On the other hand, parents who already have children may be more confident in their skills and are better able to cope with children, which would predict that parents' happiness response is more positive for higher-order births.

\section{Marital Status and Context}

The transition to parenthood also may differ for those with and without partners. Unmarried parents may have a more stressful transition, especially right after the birth, since they may not have anyone sharing childcare duties (Davies et al. 1997). However, differences in parental wellbeing by marital status may be moderated by the welfare state. To analyze how parental wellbeing depends on the level of support for single parents, we compare the relationship between childbearing and parental well-being in two contexts - Britain and Germany. Both countries have a very high mean age at birth, 30 years in 2008 (OECD 2011), and the state offers some support for single parents in both countries. However, they exhibit strong differences in the overall context of childbearing. Britain is characterized by higher rates of non-marital childbearing, a 
more dynamic labor market, limited support for parents with children, and a predominantly private childcare system. Out-of-wedlock childbearing is less common in Germany, and although working mothers are becoming more common, the traditional German norm that mothers of young children exit the labor force is still strong. Although direct public support for parents was relatively low in Germany until 2007, total public spending has been higher and the tax code more favorable for parents in Germany than in Britain (Thevenon 2011). We hypothesize that the differences in the acceptance of out-of-wedlock childbearing and public support to parents result in parental well-being differences by marital status being greater in Britain than Germany.

\section{Mediators of Parental Happiness}

When people have children, many other aspects of their lives are also changing. Before having children, people are finding a partner, making commitments and plans, and anticipating a future together. After having children, couples are excited by the joys of the baby, but also experience changing labor force participation, income, health, leisure time, marital quality, and marital stability. These factors are also linked to parental well-being. Research conducted using crosssectional data has not been able to capture the dynamic effects of these mediating factors of fertility on happiness. Even research analyzing longitudinal data has not considered these factors at all, or has presented only results that are based on models which control for these factors (Clark et al. 2008), making it impossible to analyze their mediating role. We use data with repeated information on these factors, allowing us to analyze to what extent they mediate the impact of childbearing on parental happiness. 


\section{Research Questions}

We address the following questions:

1) What is the trajectory of parental happiness before and after the birth of a child?

2) Does the happiness trajectory before and after a child is born differ by gender of the parent, age at first birth, marital status, socioeconomic status, and parity?

3) What factors mediate the impact of children on parental well-being? We examine changes in employment, income, health, and marital status.

4) How do happiness trajectories of parents differ in Germany and Britain?

\section{Data}

We use the German Socio-Economic Panel (SOEP) and the British Household Panel Survey (BHPS). The SOEP is a representative longitudinal study of households including Germans living in the Old (West) and New (East) German states, foreigners, and recent immigrants to Germany. The SOEP was started in 1984, with the New German states added in 1991. The British Household Panel Survey is an annual survey consisting of a nationally representative sample of households that started in 1991.

These data sets have three key advantages for this research. First, the SOEP and the BHPS are the world's longest panel data sets which allow examining life satisfaction before and after births. This is an improvement upon prior research which has largely relied upon synthetic cohorts constructed from cross-sectional data. Second, the samples are very large, allowing for stratified analyses, and have a long follow-up. Due to the long panels, we can analyze the postbirth happiness trajectories until children reach adult ages. Alternative panel data sets which have information on fertility and subjective well-being are considerably shorter. Third, the data 
include information on other factors that are important to take into account when analyzing why life satisfaction increases and decreases, such as changes in health, marital status, income, and labor force participation.

We focus on analyzing the happiness trajectories of individuals who became parents during the observation window (1984-2009 SOEP, 1991-2008 BHPS). Therefore we exclude persons who had children before entering the surveys and those who were still childless at the end of our follow-up, limiting the sample to individuals who started the study childless and for whom we observe the first birth during the follow-up (4,903 persons in SOEP and 3,225 persons in BHPS). After additional exclusions due to missing data, our German sample consists of 4,513 people who had in total 7,602 births over an average follow-up of 12.2 years. The British sample consists of 2,689 people who experienced 4,520 births over an average follow-up of 10.2 years.

\section{Measures}

Our key outcome is the subjective well-being of parents. In the German sample, respondents were asked annually, “How satisfied are you with your life, all things considered?” Responses range from zero (completely dissatisfied) to ten (completely satisfied). In the British sample, parental well-being is measured with two questions. The first measures general happiness and is based on the question "Have you recently been feeling reasonably happy, all things considered?" with responses ranging from one (much less happy than usual) to four (more happy than usual). The other question is "How dissatisfied or satisfied are you with your life overall," with answers ranging from one (not satisfied at all) to seven (completely satisfied). The latter life satisfaction question is closer in formulation to the one used in SOEP; however the question is not asked consistently through waves. The general happiness question is measured consistently through all 
the BHPS waves. We experimented with both measures and found that the analytical results were very similar independent of the measure, with the key difference being the loss in statistical power for the sporadically measured life satisfaction. Therefore we use the general happiness measure in BHPS. ${ }^{1}$ We rescale this variable to range from zero to ten, the same range as in the SOEP well-being measure to allow comparison of the magnitude of the coefficients across BHPS and SOEP. ${ }^{2}$

\section{Other Variables}

We coded variables in the same manner to facilitate parallel analysis for the two data sets. In both surveys age (years) is recorded for each wave. A birth is indicated by a change in the number of biological children reported in the birth biography data; step-children or adopted children are excluded from the analysis. Marital status is time-varying and categorized into four groups: married/living with a spouse, divorced/separated, single, or other. Income is measured at the household level and is pre-tax income in inflation-corrected Euros or Pounds. In the German data, education is measured in years. In the British data, education is measured with six categories: university, some college, other training establishment, polytechnic education, nursing school or similar, or other. Health is measured using self-rated health with five categories in each data set. Labor force status is measured with five categories: working, unemployed, maternity leave or similar, in school, or other.

\footnotetext{
${ }^{1}$ The differences in the questions provide external validity. Research on happiness has been criticized for being sensitive to measurement, but we find our results to be robust to the way the life satisfaction question is framed.

${ }^{2}$ After this transformation the distributional characteristics are similar. The median, mean, and standard deviation of well-being in the SOEP (BHPS) are 7.0 (6.7), 7.1 (6.8) and 1.7 (1.9).
} 


\section{Empirical Approach}

We use fixed-effects linear regression models to examine changes in life satisfaction over the course of parenthood. We assume the cardinality of life satisfaction because others have found that treating life satisfaction as ordinal versus cardinal makes little difference (Ferrer-i-Carbonell and Frijters 2004) and because this allows using linear regression models which are more straightforward to interpret and more stable in the fixed-effects setting than fixed-effects models for ordinal data.

The longitudinal fixed-effects approach has several important advantages over crosssectional research. First, the approach is based on observing individual happiness trajectories over time, allowing us to analyze anticipation, short-term, and long-term changes in happiness with respect to a birth. Second, the approach allows controlling for individual-specific, timeinvariant unobserved characteristics, such as personality or genetic endowments, and eliminates the problem of selection into parenthood on happiness. Third, it allows observing the pattern of changes in life satisfaction while controlling for other changing factors, such as age, time, employment or marital status.

Our modeling approach follows that of Clark et al. (2008), with some modifications. ${ }^{3}$ Respondents' life satisfaction at time $t$ is a function of time to or after a birth, with controls for individual fixed characteristics, period effects, and time-varying covariates. The regression equation is

$$
H_{i t}=\alpha_{i}+B_{i t}^{2-3}+B_{i t}^{1}+C_{i t}+A_{i t}^{1-2}+A_{i t}^{3-4}+A_{i t}^{5-9}+A_{i t}^{10-18}+\boldsymbol{\beta}^{\prime} \mathbf{a g e} \mathbf{e}_{i t}+T_{t}+\boldsymbol{\theta}^{\prime} \mathbf{x}_{i t}+\varepsilon_{i t}
$$

\footnotetext{
${ }^{3}$ One methodological difference is that Clark et al. (2008) estimate two equations- one for the happiness trajectory before the event, another for after the event. A resulting problem is two baselines. We solve this problem by combining the equations.
} 
where $H_{i t}$ is life satisfaction for individual i at time t, $\alpha_{i}$ is the individual fixed effect; $B^{2-3}$ and $B^{1}$ are indicators capturing the deviation in happiness from the individual baseline 2-3 and 1 year (B) before a child is born; $C$ captures the deviation in happiness from the baseline in the interview following the birth of the $(C)$ child; the variables $A^{k}$ capture the deviation in happiness k years $(A)$ after the birth; ${ }^{4}$ age effects are controlled with dummies for each one-year age group; ${ }^{5} T$ captures year-specific effects (for example, unification of Germany); ${ }^{6}$ and $\mathbf{x}_{i t}$ is a vector for other time-varying covariates (health, education, income, marital status, labor force status, and birth of additional children). We include respondents in the regressions 5 years before birth, and the omitted category in time before/after birth is 4-5 years before. Thus the coefficients $B, C, A$ represent differences with respect to this baseline level measured 4-5 years before birth.

We use the above model and the full SOEP and BHPS data sets with no controls for other time-varying covariates than age to establish the general pattern of happiness before and after the first child is born (Figure 1). We estimate the model for various sub-populations to study whether the pattern differs by sex (Figure 2), age at first birth (Figure 3), marital status (Figure 4), SES (Figure 5), or parity (Figure 6). To shed light on the mediating mechanisms, we estimate the models with and without controls for the time-varying covariates (Figure 7).

An important feature of our analysis is that we focus on how having children influences well-being among those who have children. This methodological approach, pioneered by Clark et al. (2008), is limited in that we do not compare happiness of parents to those who never had a

\footnotetext{
${ }^{4}$ In the German data post-birth follow-up is up to 18 and in the British data up to 15 years. Therefore in the analysis of the British data we replace the coefficient $A_{i t}^{10-18}$ with $A_{i t}^{10-15}$.

${ }^{5}$ We also considered linear, quadratic, and cubic age specifications. The results did not change.

${ }^{6}$ We avoid the age-period-cohort identification problem (explicit controls age and period; fixed-effects for cohort) by combining three time periods for which descriptive statistics suggested no differences. Alternative ways to avoid the identification problem - for example, by using quadratic age - did not influence the results.
} 
child. Such comparisons, which are plentiful in the literature (Aassve et al. 2009; Billari 2009; Koropeckyj et al. 2007; Margolis and Myrskyla 2011), suffer from the potential bias caused by unobserved confounders such as personality and other fixed factors which may be associated with both happiness and childbearing behavior. ${ }^{7}$ Our strategy allows controlling for such factors. In addition, the strategy has allows the analysis of mediating factors over a long-term follow-up, which are impossible to do with cross-sectional data.

\section{Results}

Sample Characteristics

\section{TABLE 1}

Table 1 shows characteristics of respondents for the German and British samples. Respondents are born between 1934 and 1990 (Germany) and 1945 and 1991 (Britain). Average age at entry to the survey is 25.2 in Germany and 26.1 in Britain. Average follow-up is 12.2 years in Germany and 10.2 years in Britain, and the range of follow-up years is 4-24 years in Germany and 4-18 in Britain.

On average, respondents have 1.7 children during the data collection period. The total number of observed births is 7,602 in Germany, of which 4,513 are first and 2,268 second births. In the British data we have 4,520 births in total, 2,689 first births and 1,377 second births. Three quarters of new parents in the German sample are married/living with a spouse, while in the Britain, 90\%, are married/living with a spouse. ${ }^{8}$ Most new fathers are employed in the interview

\footnotetext{
${ }^{7}$ Kohler et al. (2005) analyzed fertility and happiness among mono- and di-zygotic twins to get at the causal relationship. However, by the time fertility decisions are made, random life events may have shaped the twins so that they differ from each other in unobservable ways.

${ }^{8}$ Excluding cohabiters would decrease the proportion in the British data below that observed in the German data. However, the regression results for partnership status (Figure 4) are not sensitive to whether cohabiters are combined with the married.
} 
following the first birth (90\% in Germany, 88\% in Britain), while the majority of mothers are on a maternity or comparable leave (51\% in Germany, 55\% in Britain). At first interview, parents' levels of life satisfaction are 7.5 in in the German and 7.0 in the British data (scale 0-10). At first birth, life satisfaction is marginally higher, decreasing again by the last interview.

\section{The Happiness Trajectory of Parents}

FIGURE 1 AND TABLE 2

First, we illustrate the importance of the fixed-effects approach by estimating the happiness trajectory of parents before and after the birth of a first child using three different methods widely used in analysis of longitudinal surveys: (a) the pooled OLS technique which treats the data as a series of cross-sectional surveys; (b) a random-effects (RE) specification for the individual heterogeneity; (c) a fixed-effects (FE) model which controls for all fixed characteristics of the individual. We also estimate the FE model for the British data using both measures of happiness, general happiness (our preferred measure) and life satisfaction (nonpreferred, due to sporadic measurement). Table 2 shows the regression coefficients for each of these models and Figure 1 illustrates the results by charting the coefficients for the happiness trajectories at seven points in time relative to the period 4-5 years before the birth of a child (the coefficients $\left.B^{2-3}, B^{1}, C, A^{1-2}, A^{3-4}, A^{5-9}, A^{10-18}\right) .{ }^{9}$ For example, if the coefficients $B_{i t}^{1}, C_{i t}$ were 0.4 , and 0.5 , then compared to the time 4-5 years before the first child is born, people are on average 0.4 , and 0.5 units (on a scale of $0-10$ ) happier one year before and the year when the first child is born.

\footnotetext{
${ }^{9}$ These models include the observed characteristics at baseline (year of birth, sex, education, labor force status, marital status, health), but do not control for fixed-effects or time-varying factors. However, the differences between the OLS, RE and FE models would be similar even if time-varying controls were introduced (see Figure 7).
} 
We find different patterns across the three model specifications (OLS, RE, FE) indicating important unmeasured individual characteristics that affect patterns of parental well-being. The pooled OLS and RE models show a pattern in which parental well-being increases before birth and then decreases steadily after childbirth. However, in the models which include individual fixed-effects we find a very different trajectory. In the year before a child is born, parental happiness increases strongly and stays high the year the child is born. One to two years after the child is born, parental happiness drops to levels similar to 4-5 years before the birth. Happiness continues to stay at this level when the first child is young and much care is needed through when the child reaches adult ages. The coefficients for the control variables (shown in Table 2) are similar across model specifications and in the expected direction: good health, high education, and being employed or married are associated with higher happiness. The results are similar in Germany and Britain. In the British data the results are also similar across the two happiness measures, suggesting that no harm is done by using the more consistently measured general happiness measure, instead of life satisfaction.

Figure 1 illustrates the power of the FE model in reducing bias due to unobserved heterogeneity. The pooled OLS results are likely biased because of unobserved selection as the model is based on between-individual differences. Then RE model might be acceptable if the point estimates were similar to the FE model, but here they clearly differ and the Hausmann test rejects the RE specification (results not shown). Therefore in the following we report results only for the FE models. 
Happiness Trajectories by the Gender of Parent

\section{FIGURE 2}

Next, we explore whether the happiness trajectories of new parents differ by the gender of the parent. In Figure 2, we see the same overall happiness trajectory for women and men, with two main differences. First, in both Britain and Germany, women gain more in happiness in expectation and right after the birth of a child (the gender differences are statistically significant in both data sets with $\mathrm{p}<.05)$. Women also have steeper drops between the year of the birth and the year afterward. However, in the long-run, the differences between men and women are small.

Happiness Trajectories by the Age at Becoming a Parent

\section{FIGURES 3A AND 3B}

We next chart happiness trajectories by age at first birth in Figures 3A (men and women combined, separately for SOEP and BHPS) and 3B (by sex, SOEP only, due to the high degree of similarity between the results). We categorize respondents into young (18-22 years), adult (23-34), and mature (35 and older) parents by age at first birth. ${ }^{10}$ The youngest category includes those in the border of adulthood who may still be in school or are in the very early stages of their careers. The adult category includes the prime childbearing years. At these ages people have often completed their education and are starting their careers. The third category, mature parents, includes ages at which people typically have accumulated socioeconomic resources, completed their education, and started their careers. In short, they have achieved their socioeconomic

\footnotetext{
${ }^{10}$ Very young parents (aged 17 or less) are excluded because (i) teenage childbearing is a different process than having children at young adult ages; (ii) our samples include very few people who had children before turning 18; (iii) it is difficult to construct a meaningful pre-birth baseline happiness for teen parents.
} 
position. On the other hand, at these ages the aging-related risks to healthy childbearing start to increase, particularly for women (Heffner 2004)

Young parents have a pattern of decreasing well-being up to the birth of a child, when happiness climbs back to the baseline (Figure 3A). After the birth, the trajectory is negative. Those who become parents at ages 23-34 have increasing happiness before the first birth and in the year of the birth, but 1-2 years afterwards happiness decreases to its initial level. Those who become parents at ages 35-49 have increasing happiness before and during the year of the birth, and then despite a small drop, happiness remains above the baseline. A test for whether the coefficients for 3-4, 5-9 and 10-18 years after birth are all zero suggests significantly increased long-run happiness $(\mathrm{p}<.05)$ in Germany and borderline significant $(\mathrm{p}<.10)$ in Britain.

Figure 3B shows the happiness trajectories by age at first birth and sex in the SOEP data. Both men and women that are older when becoming parents gain the most. The differences between 23-34 and 35-49 year old first-time parents are particularly strong for women, and the trajectories for young parents are particularly poor for young fathers.

Happiness Trajectories by Partnership Status.

\section{FIGURE 4}

Figure 4 charts the parental happiness trajectories by marital status at the time of birth, comparing those who were partnered to those who were not. In both groups, happiness increases in expectation of birth, then decreases close to the pre-birth levels. The differences by partnership status appear small in Germany, where the only difference is that the partnered are somewhat happier than un-partnered in the year before the birth $(\mathrm{p}<.10)$. In the year before a birth, people may be happy in their partnerships, perhaps are newly married, and are planning a 
life together. In Britain, the differences are larger. Partnered British have larger increases in happiness before the birth, in the year a first child is born, and have upward happiness trajectories as their children grow up. Un-partnered British experience smaller increases in happiness surrounding the birth and they do not experience long-run increases in happiness postbirth. Thus while the differences by marital status are substantial and significant in Britain, in Germany the differences are small and only marginally significant.

The following sections analyze parental happiness trajectories by education and parity, and consider the role of mediating factors between fertility and happiness. The results are highly similar between the German and British data sets; therefore we present the results only for the larger German data. We note any differences between the German and British results.

Happiness Trajectories by Educational Attainment

\section{FIGURE 5}

Figure 5 plots the trajectory by educational attainment, with "high education" being defined as 12 or more years of schooling. Men with high educational attainment gain more happiness from a first birth than their less educated peers in expectation, after birth, and in the long-run. These education differences are statistically significant $(\mathrm{p}<.05)$. For women, we see no differences in parental happiness trajectories by educational attainment. The results (not shown) are similar in the British data. ${ }^{11}$

\footnotetext{
${ }^{11}$ We found the same pattern in both countries for income as education.
} 
Happiness Trajectories by Parity

\section{FIGURE 6}

To this point, we have focused on a first birth. We now turn to differences by parity. Figure 6 plots the parental well-being trajectories with respect to the birth of a child for first, second, and third births with the German data. The regressions are stratified by parity so parents are in multiple regression equations if they had more than one birth. We control for the influence of previous births; without these, the baseline level, estimated as 4-5 years before the birth for all parities, would be influenced by the previous births.

For first births, parents’ happiness trajectories increase sharply before and around the birth and then settle close to pre-birth levels. For second births, the overall trajectory is similar, but the increase in happiness before and around the birth is markedly lower than for first births. For third births, the pattern is qualitatively different. Third births have no positive effects, and may in the long-run be associated with decreased happiness. In the British data, the results (not shown) were similar for first and second births, but for third births the happiness trajectory was flat.

\section{Mediating Factors}

\section{FIGURE 7}

In the last part of our analysis, we examine whether changes in health, income, labor force status, and marital status mediate the influence of children on parents' happiness trajectories. We compare results of models which do and do not control for these time-varying factors. Figure 7 shows the results for the German data. For both men and women, the happiness trajectories surrounding a first birth are very similar with and without controls for the time-varying factors. 
In particular, the increase in happiness at around the time of birth is only marginally (and not significantly) attenuated when the controls are introduced, and there are no differences in the long-term trajectories. The period when the controls make the most difference is the time just before and after the birth. This may be because the changes in marital status are picking up the happiness of partnering, planning a future together, and anticipation of childbearing. These results, which are similar in the British data, suggest that by and large the influence of children on happiness is not mediated by changes in income, health, marital status or labor force status.

\section{Sensitivity Analysis}

We conducted several robustness checks. First, we estimated the key results using a multinomial logit (instead of linear) model to make sure that our results are not influenced by the cardinality assumption of the happiness measures. The results were consistent with those obtained with the linear model. Second, we stratified the analysis by final parity $(1,2$, or 3 or more children) at age 40, excluding those for whom the follow-up ended earlier, and found similar results. Third, we studied whether the happiness trajectories with respect to the second and third children depend on birth spacing. The results by parity held independently of the time to the previous birth. Fourth, we considered whether the happiness trajectories with respect to the second child are the same in a new union, compared to having the first and second child in the same union. In these analyses the data got thin and we were not able to refute the null hypothesis that the pattern is the same for both groups.

Finally, we considered dynamic panel data models which under certain conditions provide more accurate confidence intervals or less biased coefficients. First, we allowed the individual-level error term to be autocorrelated (AR(1)), which corrects for biased confidence 
intervals if there is autocorrelation net of the covariates. The results changed only marginally. Second, we considered dynamic panel data models which take into account the possibility of reverse causation. The positive association between childbearing and happiness could be driven by the fact that happiness increases the probability of having a child, rather than the process of having a child increasing happiness. We first used a simple and intuitive check to test whether past happiness confounds the association between childbearing and current happiness by including lagged happiness (up to 3 years) as controls in the models. The results changed only marginally. Third, we used the standard Arellano-Bond dynamic panel models that add both lagged dependent variables to the model and instruments the key regression variables with their own lags to account for reverse causality (Arellano and Bond 1991). We considered various specifications of lag structures and results were nearly identical to those obtained without the dynamic structure. Results from these further analyses are available upon request.

\section{Discussion}

Having children increases happiness. The increase associated with a first birth is mostly short-term, but it is clearly an increase, making the net effect positive. However, this overall pattern is strongly modified by sociodemographic characteristics. Those who become parents at young ages have a downward happiness trajectory, while those postponing parenthood have a higher happiness level post-birth. Socioeconomic resources are important for men, as those with low education gain little in happiness from the birth of a child. Moreover, the first child increases happiness a lot, the second less, and the third may decrease happiness. These three key findings temporary gains in happiness around the time of birth; strong modifying impact of parental sociodemographic characteristics; and differences by parity - were similar in Britain and 
Germany. The results suggest that children, in particular the first two, increase happiness most among those who postpone and have more resources. This pattern is highly consistent with the fertility behavior emerging during the second demographic transition and provides new insights into the causes of low and late fertility. The fact that older parents' well-being increases with childbearing, but young parents have downward happiness trajectories may explain why postponing fertility has become so common. That parents experience increases in well-being for the first two children but not the third, may explain why so few go on to have a third.

Our first key finding that happiness increases temporarily around a first birth and then decreases back to pre-birth levels, differs from many which find that parents are more distressed and more unhappy than the childless (Gore and Mangione 1983; McLanahan and Adams 1987). The main reason for this difference may be that we compare the happiness levels of parents and non-parents by comparing the same people before and after they have a child, whereas other studies often base their results on comparing different individuals. We argue that the latter strategy is potentially biased because unobserved characteristics which influence both childbearing decisions and well-being confound the association. Thus the difference is likely due to our superior analytic strategy which accounts for unobserved, fixed characteristics such as personality or genetic endowments that may correlate with both childbearing and happiness. As shown in Figure 1, not accounting for such unobserved heterogeneity seriously biases the results. The magnitude of the change in well-being around the time of a first birth is substantial. Happiness is, on average, 0.3-0.5 units higher (on 0-10 scale) when a child is born compared to the baseline 4-5 years earlier. This magnitude is comparable to the effect of divorce (-0.49), going to from employed to unemployed (-0.47), or one unit increase in health on a 5-point scale $(-0.36)$ (results based on the fixed-effects regression shown in Figure 7). 
Our second key finding highlights how parental well-being trajectories vary by parental characteristics. In particular, those who become parents at young ages have a downward happiness trajectory, while those who become parents at older ages and men with more resources have more positive short- and long-term responses to a birth. Older parents may be more "ready" for parenthood, or may have been anticipating it more intently (Gregory 2007). The finding that men with high and low socioeconomic status have such different parental happiness trajectories may help understand the divergence in mental health by socioeconomic status.

Socioeconomic resources may be particularly important for men because they take more responsibility of the economic and financial well-being of the household than women. Alternatively, highly educated women may feel more "role captivity" than less educated moms. Nomaguchi and Brown (2011) find that although highly educated moms experience less parenting stress than less educated moms, they have a stronger sense of isolation from the adult world. This may partially account for the similar trajectories for women by educational attainment.

The age gradient in the happiness response to a birth sheds new light on the set point theory of happiness, which posits that after short-term fluctuations due to life events, happiness converges back to the initial level (Brickman and Campbell 1971). When averaged over the whole population, the parental happiness trajectories return to pre-birth levels, consistently with the set point theory. However, we find medium-term increases in parental happiness around a birth which are by no means negligible. Moreover, not all subgroups converge back to their baseline levels. In particular, we observed that the birth of a child may have long-term negative consequences for young parents but positive consequences for older parents. Although set point 
theory might hold on average, there is important heterogeneity in the long-term happiness response to having a child.

The documented age gradient suggests that becoming a parent at older ages is better for well-being than having the child at a young age. This is helpful for understanding the postponement of childbearing. The gradient, however, is estimated conditional on having a child. Fecundity declines and the risk of involuntary childlessness increase with age, particularly for women. Our results only pertain to those for whom this risk did not realize.

Our third key finding is that the happiness impact of children attenuates with parity, being strongest for the first, lower for the second, and non-positive for the third child. Perhaps the positive response to a birth is strongest when the experience is new, or higher-order births have a weaker impact because they are less likely to be planned (Hayford and Guzzo 2010). Independently of the mechanism, these results accord with qualitative work suggesting that the balance of negative and positive experiences is important when deciding to have an additional child (Newman 2008), and help explain why most people have one or two children even when the net economic costs to the parents are substantial.

Women anticipate a first birth more than men, with stronger happiness increases prior to and around the birth, and a larger drop afterwards. The gender differences may be driven by physiological responses, such as increased levels of a stress-relief hormone oxytocin during pregnancy and after birth (Ryan and Deci 2001) or because women are often the primary caregiver when children are very young, therefore being at higher risk of sleep-deprivation and social isolation (Della Giusta et al. 2011; Simon 1992). In future work we will examine the mechanisms for this gender difference. 
The parental happiness trajectories are markedly similar in Britain and Germany, with one major exception. German parents had similar happiness trajectories, whether partnered or un-partnered. However, in Britain, partnered parents experience markedly larger short- and longrun increases in happiness in response to a birth than the un-partnered. The differences by partnership status of British and German parents may reflect differences in the tax and family policies available for unmarried parents, or differences in the social stigma related to out-ofwedlock childbearing and single parenthood. Both carry a stigma in western parts of Germany, but out-of-wedlock childbearing is also relatively rare in these regions. In contrast, out-ofwedlock childbearing is relatively common in eastern parts of Germany, and socially more acceptable (Konietzka and Kreyenfeld 2002). This may diminish the differences in the wellbeing trajectories in Germany between the partnered and un-partnered, when compared to the difference in Britain. Thus social norms and social policy may play some role in shaping parental well-being trajectories, but overall the individual sociodemographic characteristics seem much more important than context.

Many other things are changing for new parents when a child is born. We examined whether changes in employment, partnership status, income, and health mediate the impact of children on happiness. For example, happiness may increase before a birth because of a new partnership, and decrease afterwards because dropping out of work. We found that overall, these factors do little to mediate the effects of childbearing on happiness.

Our findings open several new research questions. First, the mechanism through which children influence well-being is not well understood; possible mechanisms could be biological and social. Analyzing the former requires information on biomarkers. For social mechanisms, qualitative information on work-family conflict, planning status of births, and instrumental 
support would be informative. Second, the social norms about childbearing have relaxed markedly over the study period. Future research could consider whether this has changed the experience of parenthood. Third, we mapped the happiness trajectories for parents; the remaining question is how these trajectories compare to those who choose to be childless or are involuntarily childless.

We conclude that the process of childbearing is an important factor for well-being. The way in which children influence parental happiness depends on the individual characteristics of parents and number of previous children. Our results suggest that those who gain from childbearing most are those who have 1-2 children at an older age after acquiring educational and financial resources. This is consistent with the fertility behavior that emerged during the second demographic transition in developed countries (van de Kaa et al 2003; McDonald 2000). If men and women perceive that they will be better off postponing parenthood, then parental well-being trajectories can provide new insights into the causes of low and late fertility. 


\section{References}

Aassve, A., A. Goisis and M. Sironi. 2009. "Happiness and Childbearing Across Europe." Social Indicators Research:1-22.

Adema, W. and P. Whiteford. 2007. Babies and Bosses: Reconciling Work and Family Life: A Synthesis of Findings for OECD Countries. Vol. 4.Publications de l'OCDE.

Adserà, A. 2004. "Changing Fertility Rates in Developed Countries. the Impact of Labor Market Institutions." Journal of Population Economics 17(1):17-43.

Alvergne, A., M. Jokela, and V. Lummaa. 2010. "Personality and reproductive success in a highfertility human population. Proceedings of the National Academy of Sciences 107(26): 11745-11750.

Angeles, L. 2010. "Adaptation and Anticipation Effects to Life Events in the United Kingdom." University of Glasgow, Department of Economics Discussion Paper 08

Arellano, M. and S. Bond. 1991. "Some tests of specification for panel data: Monte Carlo evidence and an application to employment equations.” The Review of Economic Studies 58: 277- 297.

Avison, W.R. and L.Davies. 2005. "Family Structure, Gender, and Health in the Context of the Life Course." The Journals of Gerontology Series B: Psychological Sciences and Social Sciences 60(Special Issue 2):S113-S116.

Baranowska, A. and A. Matysiak. 2011. "Does Parenthood Increase Happiness? Evidence for Poland." Vienna Yearbook of Population Research 2011, p. 307 - 325.

Billari, F. C. 2009. "The Happiness Commonality: Fertility Decisions in Low-Fertility Settings." Keynote address to panel on "Very low fertility" Conference on How Generations and Gender Shape Demographic Change: Toward policies based on better knowledge, UNECE, 
Geneva, 14-16 May. «http://www.unece.org/fileadmin/DAM/pau/_docs/ggp/2008/ GGP_2008_GGConf_Publ_1_Chapter-1.pdf ».

Brickman, P., and Campbell, D. T. 1971. Hedonic relativism and planning the good society. In M. H. Appley (Ed.), Adaptation-level theory (pp. 287-305). New York: Academic Press.

Clark, A. E., E. Diener, Y. Georgellis and R. E. Lucas. 2008."Lags and Leads in Life Satisfaction: A Test of the Baseline Hypothesis." The Economic Journal 118(529):F222-F243.

Clark, A. E. and Y. Georgellis. 2010. "Back to Baseline in Britain: Adaptation in the BHPS." PSE working paper no.02. Paris school of economics.

Cleary, P. D. and D. Mechanic. 1983. "Sex Differences in Psychological Distress among Married People." Journal of Health and Social Behavior:111-121.

Connidis, I. A. and J. A. McMullin. 1993. "To have Or have Not: Parent Status and the Subjective Well-being of Older Men and Women." The Gerontologist 33(5):630.

Davies, L., W. R. Avison and D. D. McAlpine. 1997. "Significant Life Experiences and Depression among Single and Married Mothers." Journal of Marriage and the Family:294308.

De Neve, J. 2011. “Functional Polymorphism (5-HTTLPR) in the Serotonin Transporter Gene is Associated with Subjective Well-Being: Evidence from a U.S. Nationally Representative Sample” Journal of Human Genetics. 56:456-459.

Della Giusta, M., S. L. Jewell and U. S. Kambhampati. 2011. "Gender and Life Satisfaction in the UK." Feminist Economics 17(3):1-34

Edin, K. and M. Kefalas. 2005. "Promises I can Keep: Why Poor Woman Put Motherhood Ahead of Marriage." Berkeley: University of California Press. 
European Commission. 2006. "White paper "The demographic future of Europe - from challenge to opportunity.”" Commission of the European Communities, Directorate-General for Employment, Brussels.

Ferrer-i-Carbonell, A. and P. Frijters. 2004. "How Important is Methodology for the Estimates of the Determinants of Happiness?" The Economic Journal 114(497):641-659.

Feyrer, J., B. Sacerdote and A. D. Stern. 2008. "Will the Stork Return to Europe and Japan? Understanding Fertility within Developed Nations." The Journal of Economic Perspectives 22(3):3-2A.

Frijters, P., D. W. Johnston and M. A. Shields. 2011. "Life Satisfaction Dynamics with Quarterly Life Event Data." Scandinavian Journal of Economics 113(1):190-211.

Gauthier, A. H. 2007. "The Impact of Family Policies on Fertility in Industrialized Countries: A Review of the Literature." Population Research and Policy Review 26(3):323-346.

Gore, S. and T. W. Mangione. 1983. "Social Roles, Sex Roles and Psychological Distress: Additive and Interactive Models of Sex Differences." Journal of Health and Social Behavior:300-312.

Gregory, E. 2007. Ready: Why Women are Embracing the New Later Motherhood. Basic Books. Harknett, K. and J. Knab. 2007. "More Kin, Less Support: Multipartnered Fertility and Perceived Support among Mothers." Journal of Marriage and Family 69(1):237-253.

Hayford, S.R. and K.B. Guzzo. 2010. “Age, relationship status, and the planning status of births.” Demographic Research 23(13):365-398.

Heffner, L. 2004. “Advanced maternal age - How old is too old?” The New England Journal of Medicine 351 (19): 1927-1929. 
Hobcraft, J. 2006. "The ABC of Demographic Behaviour: How the Interplays of Alleles, Brains, and Contexts Over the Life Course should Shape Research Aimed at Understanding Population Processes." Population Studies 60(2):153-187.

Kohler, H.P., J. R. Behrman and A.Skytthe. 2005. "Partner Children= Happiness? The Effects of Partnerships and Fertility on Well-Being." Population and Development Review 31(3):407-445.

Konietzka, D. and M. Kreyenfeld 2002. "Women’s employment and non-marital childbearing: A comparison between East and West Germany in the 1990s." Population-E 57: 331-358.

Koropeckyj-Cox, T., A. M. Pienta and T. H. Brown. 2007. "Women of the 1950s and the" Normative" Life Course: The Implications of Childlessness, Fertility Timing, and Martial Status for Psychological Well-being in Late Midlife." The International Journal of Aging and Human Development 64(4):299-330.

Larsen, R. J. 2000. Toward a science of mood regulation. Psychological Inquiry, 11, 129-141. Lovell-Troy, L. A. 1983. "Anomia among Employed Wives and Housewives: An Exploratory Analysis." Journal of Marriage and the Family:301-310.

Lykken, D. and Tellegen, A. 1996. Happiness is a stochastic phenomenon. Psychological Science, 7, 186-189.

Macdonald, C. L. 2011. Shadow Mothers: Nannies, Au Pairs, and the Micropolitics of Mothering.Univ of California Press.

Margolis, R. and M. Myrskylä. 2011. "A Global Perspective on Happiness and Fertility." Population and Development Review 37(1):29-56.

McDonald, P. 2000. "Gender Equity in Theories of Fertility Transition." Population and Development Review 26(3):427-439. 
McLanahan, S. and J. Adams. 1987. "Parenthood and Psychological Well-being." Annual Review of Sociology:237-257.

Newman, L. 2008. “How parenthood experiences influence desire for more children in Australia: A Qualitative Study” Journal of Population Research 25(1): 1-27.

Nomaguchi, K.M., and S.L. Brown. 2011. "Parental Strains and Rewards among Mothers: The Role of Education” Journal of Marriage and Family 73:621-636.

OECD 2011. OECD Family Database.OECD Social Policy Division, Directorate of Employment, Labour and Social Affairs, http://www.oecd.org/dataoecd/62/49/41919586.pdf.

O'Hara, M. W. 2009. "Postpartum Depression: What we Know." Journal of Clinical Psychology 65(12):1258-1269.

Rempel, J. 1985. "Childless Elderly: What are they Missing?" Journal of Marriage and the Family:343-348.

Rogers, J.L., H.P. Kohler, K.O. Kyvik, and K. Christensen. 2001. Behavior Genetic Modeling of Human Fertility: Findings From a Contemporary Danish Twin Study. Demography $38(1): 29-42$.

Ross, C. E. and J. Huber. 1985. "Hardship and Depression." Journal of Health and Social Behavior:312-327.

Ryan, R. M. and E. D. Deci. 2001. “On Happiness and Human Potentials: A Review of Research on Hedonic and Eudaimonic Well-Being Oxytocin.” Annual Review of Psychology 52:141166

Simon, R. W. 1992. "Parental Role Strains, Salience of Parental Identity and Gender Differences in Psychological Distress." Journal of Health and Social Behavior: 25-35. 
Sobotka, T. 2004. "Is Lowest-Low Fertility in Europe Explained by the Postponement of Childbearing?" Population and Development Review 30(2):195-220.

Sobotka, T. and W. Lutz. 2011. "Misleading Policy Messages Derived from the Period TFR: Should we Stop using it?" Comparative Population Studies-Zeitschrift Für Bevölkerungswissenschaft 35(3).

Thévenon, O. 2011. "Family Policies in OECD Countries: A Comparative Analysis." Population and Development Review 37(1):57-87.

Turney, K. 2011. "Chronic and Proximate Depression among Mothers: Implications for Child Well-Being." Journal of Marriage and Family 73(1):149-163.

Van de Kaa, D., P. Demeny and G. McNicoll. 2003. "Second Demographic Transition." Encyclopedia of Population. New York: McMillan Reference USA. 
Table 1. Sample characteristics. SOEP: German Socio-Economic Panel waves 1984-2009; BHPS: British Household Panel Survey waves 1991-2008.

\begin{tabular}{|c|c|c|c|c|c|c|}
\hline & SOEP & & & BHPS & & \\
\hline Demographic characteristics & Total & Men & Women & Total & Men & Women \\
\hline Number of respondents (\%) & 4513 & $1927(43 \%)$ & $2586(57 \%)$ & 2689 & $1310(49 \%)$ & $1379(51 \%)$ \\
\hline Age at entry, mean (SD) & $25.2(5.4)$ & $27.0(5.6)$ & $23.8(4.9)$ & $26.1(5.8)$ & $27.5(5.7)$ & $24.7(5.5)$ \\
\hline -- Range (min, max) & 15,55 & 16,55 & 15,47 & 15,52 & 16,52 & 15,41 \\
\hline Year of birth, mean (SD) & $1968.7(7.7)$ & $1967.4(8.0)$ & $1969.7(7.4)$ & $1970.7(7.5)$ & $1969.4(7.3)$ & $1972.1(7.5)$ \\
\hline -- Range (min, max) & 1934, 1990 & 1934, 1990 & 1936, 1989 & 1945, 1991 & 1945, 1990 & 1950, 1991 \\
\hline Years of follow-up, mean (SD) & $12.2(6.1)$ & $12.8(6.1)$ & $11.7(6.0)$ & $10.2(5.0)$ & $10.0(4.9)$ & $10.3(5.0)$ \\
\hline -- Range (min, max) & 4,24 & 4,24 & 4,24 & 4,18 & 4,18 & 4,18 \\
\hline Number of children, mean (SD) & $1.68(0.70)$ & $1.69(0.70)$ & $1.67(0.70)$ & $1.70(0.69)$ & $1.68(0.68)$ & $1.71(0.69)$ \\
\hline \multicolumn{7}{|l|}{$\begin{array}{l}\text { Births observed during the } \\
\text { follow-up }\end{array}$} \\
\hline -- Total & 7602 & 3268 & 4334 & 4520 & 2177 & 2343 \\
\hline$--1^{\text {st }}$ births & 4513 & 1927 & 2586 & 2689 & 1310 & 1379 \\
\hline$--2^{\text {nd }}$ births & 2268 & 991 & 1277 & 1377 & 659 & 718 \\
\hline$--3^{\text {rd }}$ births & 536 & 230 & 306 & 295 & 134 & 161 \\
\hline$--4^{\text {th }}$ and higher order & 285 & 120 & 165 & 159 & 74 & 85 \\
\hline \multicolumn{7}{|l|}{$\begin{array}{l}\text { Characteristics when the } 1 \text { st } \\
\text { child is born }\end{array}$} \\
\hline $\begin{array}{l}\text { Married or living with a } \\
\text { spouse, \% }\end{array}$ & $75.4 \%$ & $77.9 \%$ & $73.5 \%$ & $91.9 \%$ & $96.5 \%$ & $87.6 \%$ \\
\hline Health, mean (SD) ${ }^{\mathrm{a}}$ & $2.09(0.79)$ & $2.11(0.80)$ & $2.08(0.78)$ & $2.00(0.86)$ & $1.93(0.83)$ & $2.07(0.88)$ \\
\hline Income/1000, mean $(\mathrm{SD})^{\mathrm{b}}$ & $38.8(28.4)$ & $40.6(26.9)$ & $37.5(29.4)$ & $30.3(19.8)$ & $30.3(19.6)$ & $30.2(20.0)$ \\
\hline \multicolumn{7}{|l|}{ Labor Force Status } \\
\hline -- Employed & $48 \%$ & $90 \%$ & $17 \%$ & $62 \%$ & $88 \%$ & $37 \%$ \\
\hline -- Unemployed & $4 \%$ & $5 \%$ & $3 \%$ & $7 \%$ & $9 \%$ & $5 \%$ \\
\hline -- Maternity leave or similar & $30 \%$ & $1 \%$ & $51 \%$ & $28 \%$ & $1 \%$ & $55 \%$ \\
\hline $\begin{array}{l}\text {-- Other outside labour force } \\
\text { (e.g., student, housewife, retired) }\end{array}$ & $18 \%$ & $3 \%$ & $28 \%$ & $3 \%$ & $3 \%$ & $3 \%$ \\
\hline $\begin{array}{l}\text { Education, (SOEP): years (SD); } \\
\text { (BHPS) Proportion with some } \\
\text { college or university }\end{array}$ & $12.1(2.7)$ & $12.2(2.8)$ & $12.0(2.6)$ & $57 \%$ & $54 \%$ & $60 \%$ \\
\hline $\begin{array}{l}\text { Happiness: life satisfaction in } \\
\text { SOEP, general happiness in }\end{array}$ & & & & & & \\
\hline BHPS, mean $(S D)^{\mathrm{C}}$ & & & & & & \\
\hline -- First interview & $7.47(1.70)$ & $7.44(1.64)$ & $7.50(1.75)$ & $6.99(1.88)$ & $7.08(1.72)$ & $6.91(2.02)$ \\
\hline -- When the $1^{\text {st }}$ child is born & $7.56(1.60)$ & $7.47(1.57)$ & $7.62(1.63)$ & 7.21 (2.09) & $7.19(1.91)$ & $7.24(2.26)$ \\
\hline -- Last interview & $6.95(1.70)$ & $6.90(1.69)$ & $7.00(1.72)$ & $6.60(1.91)$ & $6.67(1.73)$ & $6.54(2.06)$ \\
\hline
\end{tabular}

Notes

a. Measured on a scale from 1 (Excellent) to 5 (Poor)

b. SOEP: Income is measured at the household level and refers to pre-tax income in inflation-corrected Euro. BHPS: Income is measured at the household level and refers to pre-tax income in inflation-corrected Pounds.

c. Scale both in SOEP and BHPS from 0 (Poor) to 10 (Excellent). 
Table 2. Happiness trajectory of parents before and after the birth of the first child. Ordinary least squares (OLS), random-effects (RE) and fixed-effects (FE) regression models. SOEP = German Socioeconomic Panel, N=4,513 with 54,976 person years; BHPS = British Household Panel Survey, $N=2,689$ with 27,307 person years. Figure 1 illustrates the happiness trajectories.

\begin{tabular}{|c|c|c|c|c|c|c|c|}
\hline & SOEP & & & BHPS & & & \\
\hline & OLS & $\mathrm{RE}$ & $\mathrm{FE}$ & OLS & $\mathrm{RE}$ & $\begin{array}{c}\text { FE, gen. } \\
\text { happ. }^{\text {a }}\end{array}$ & $\begin{array}{c}\text { FE, life } \\
\text { sat. }^{\text {b }}\end{array}$ \\
\hline \multicolumn{8}{|l|}{ Time to/after the birth } \\
\hline 4-5 years before (ref) & 0 & 0 & 0 & 0 & 0 & 0 & 0 \\
\hline 2-3 years before & 0.04 & $0.05^{\mathrm{t}}$ & $0.08^{*}$ & $-0.11 *$ & $-0.10^{\mathrm{t}}$ & 0.01 & 0.05 \\
\hline 1 year before & $0.23^{* * *}$ & $0.24^{* * *}$ & $0.30 * * *$ & $0.19 * *$ & $0.22 * * *$ & $0.40^{* * *}$ & $0.42 * * *$ \\
\hline 1st child born & $0.25 * * *$ & $0.28 * * *$ & $0.32 * * *$ & $0.20 * *$ & $0.24 * * *$ & $0.47 * * *$ & $0.39 * * *$ \\
\hline 1-2 years after & $-0.07^{\mathrm{t}}$ & -0.05 & 0.05 & $-0.33^{* * *}$ & $-0.29 * * *$ & 0.01 & 0.07 \\
\hline 3-4 years after & $-0.13 * *$ & $-0.09 *$ & 0.03 & $-0.38 * * *$ & $-0.34 * * *$ & 0.04 & 0.06 \\
\hline 5-9 years after & $-0.19 * * *$ & $-0.15 * *$ & 0.02 & $-0.41 * * *$ & $-0.36 * * *$ & 0.15 & 0.13 \\
\hline $10-15 / 18$ years after $\wedge a$ & $-0.27 * * *$ & $-0.22 * * *$ & 0.02 & $-0.55^{* * *}$ & $-0.53 * * *$ & 0.13 & 0.21 \\
\hline \multicolumn{8}{|l|}{ Marital status (ref: married) } \\
\hline Single & -0.05 & $-0.10^{* *}$ & . & 0.04 & 0.04 & . & . \\
\hline Divorced/Separated & -0.13 & $-0.17^{\mathrm{t}}$ & . & 0.03 & 0.04 & . & . \\
\hline Other (e.g. widowed, unknown) & -0.42 & $-0.55^{*}$ & . & -0.46 & -0.70 & . & . \\
\hline \multicolumn{8}{|l|}{ Labor force status (ref: working) } \\
\hline Unemployed & $-0.25^{* *}$ & $-0.31 * * *$ & . & $-0.20 *$ & $-0.19 *$ & . & . \\
\hline Maternity leave or similar & $-0.12^{t}$ & $-0.13^{*}$ & . & -0.12 & -0.12 & . & . \\
\hline In education & 0.00 & -0.06 & . & -0.14 & -0.15 & . & . \\
\hline Other (e.g. housewife, retired) & $-0.12^{\mathrm{t}}$ & $-0.17 * *$ & . & 0.05 & -0.03 & . & . \\
\hline Health (1=Excellent, 5=Poor) & $-0.39 * * *$ & $-0.40 * * *$ & . & $-0.19 * * *$ & $-0.19 * * *$ & . & . \\
\hline Log of household income & $0.08^{* * *}$ & $0.08 * * *$ & . & 0.02 & 0.01 & . & . \\
\hline Number of Years of Education & $0.05^{* * *}$ & $0.04^{* * *}$ & 0.02 & & & & \\
\hline Education (ref: some college) & & & & 0 & 0 & & \\
\hline University & & & & 0.10 & 0.15 & . & . \\
\hline Other training establishment & & & & 0.05 & 0.06 & . & . \\
\hline Polytechnic & & & & -0.03 & 0.02 & . & . \\
\hline Nursing school or similar & & & & -0.05 & 0.06 & . & . \\
\hline Other & & & & 0.05 & 0.06 & . & . \\
\hline Constant & $3.58 * * *$ & $5.93 * * *$ & $6.29 * * *$ & $6.86^{* * *}$ & $9.27 * * *$ & $11.02^{* * *}$ & $8.10^{* * *}$ \\
\hline Observations & 54976 & 54976 & 54976 & 27307 & 27307 & 27307 & 21395 \\
\hline R-squared & 0.069 & & 0.455 & 0.028 & & 0.261 & 0.532 \\
\hline Adjusted R-squared & 0.067 & & 0.404 & 0.025 & & 0.175 & 0.463 \\
\hline Number of persons & 4513 & 4513 & 4513 & 2689 & 2689 & 2689 & 2672 \\
\hline
\end{tabular}
${ }^{\mathrm{t}} \mathrm{p}<.10, * \mathrm{p}<.05,{ }^{* *} \mathrm{p}<.01,{ }^{* * *} \mathrm{p}<.001$

a. General happiness as the dependent variable. See section Data for more details.

b. Life satisfaction as the dependent variable. See section Data for more details. 
Figure 1. Happiness trajectory of parents before and after the birth of the first child. Ordinary least squares (OLS), random-effects (RE) and fixed-effects (FE) regression models. SOEP = German Socioeconomic Panel, N=4,513 with 54,976 person years; BHPS = British Household Panel Survey, $\mathrm{N}=2,689$ with 27,307 person years.

\section{German Panel SOEP}

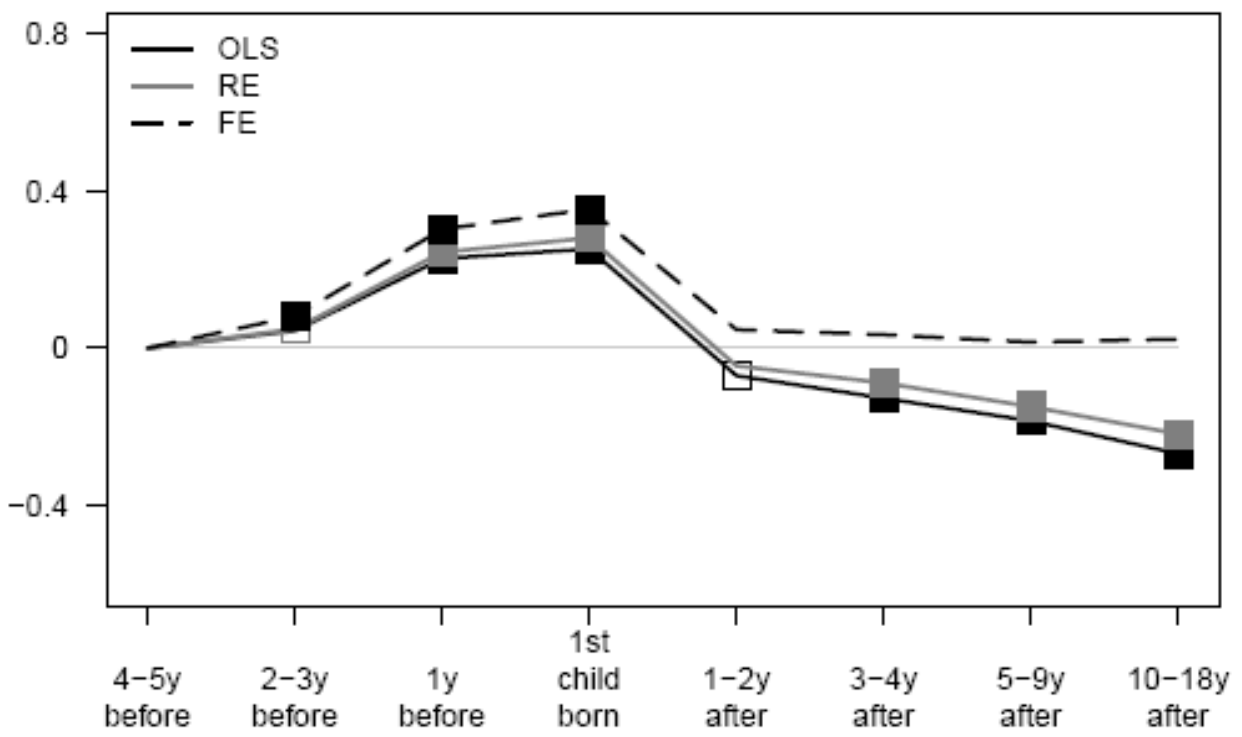

British Panel BHPS

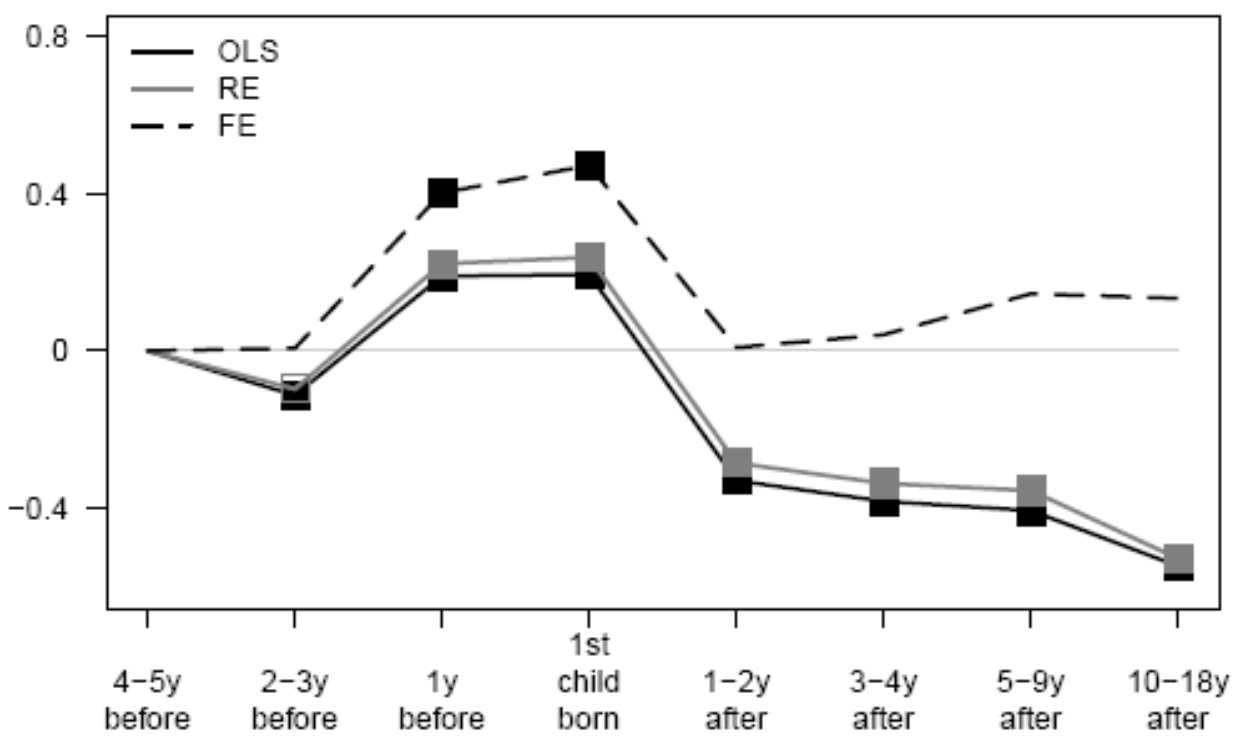

Notes

1. Dots are significant at .05 level. Shallow dots are significant at .10 level.

2. The RE and OLS models control for single-year age, period effects, and baseline characteristics education, marital status, labor force status, and health. The FE model includes as control variables only age and period dummies. Standard errors are estimated with robust methods which account for clustering within individuals.

3. For BHPS "10-18y" should be interpreted as "10-15y" since 14 years is the maximum post-birth follow-up.

4. The patterns are robust to the inclusion of time-varying controls or the specification of age. 
Figure 2. Happiness trajectory of parents before and after the birth of the first child, by country and gender. Fixed-effects linear regressions. SOEP = German Socioeconomic Panel, N=4,513 with 54,976 person years; BHPS = British Household Panel Survey, N = 2,689 with 27,307 person years.

\section{A. German Panel SOEP}

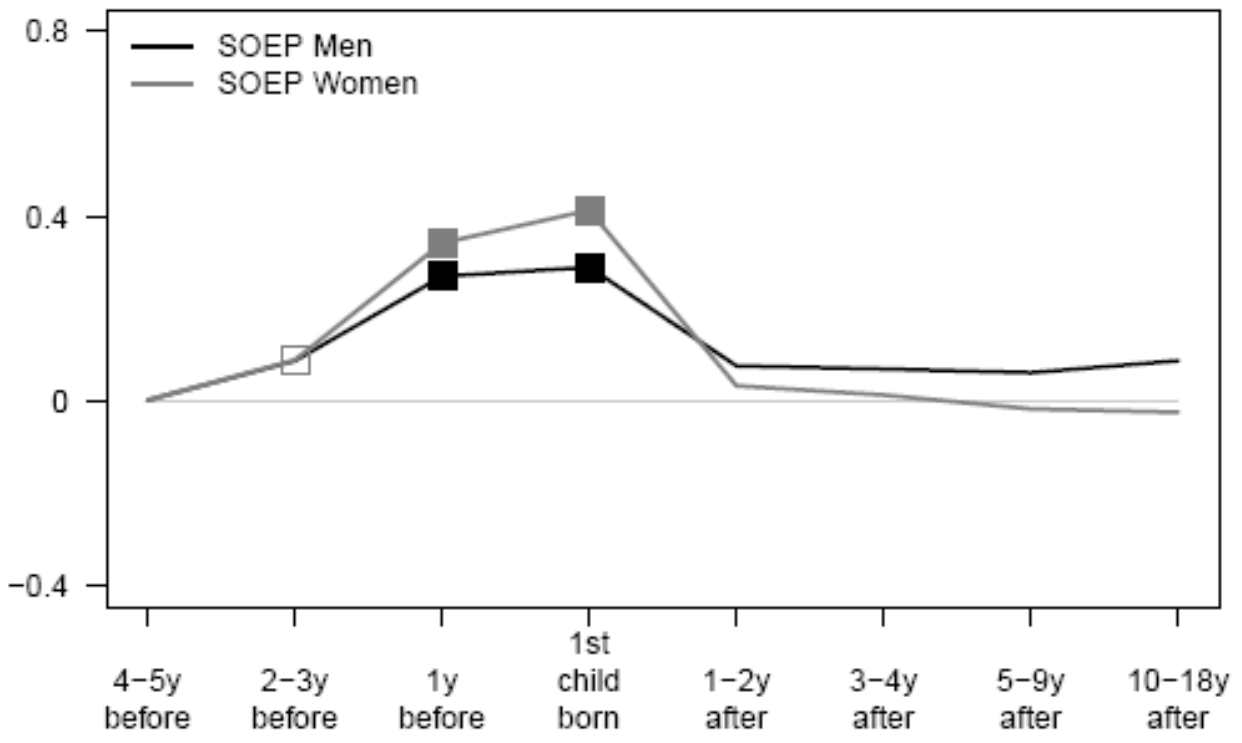

\section{B. British Panel BHPS}

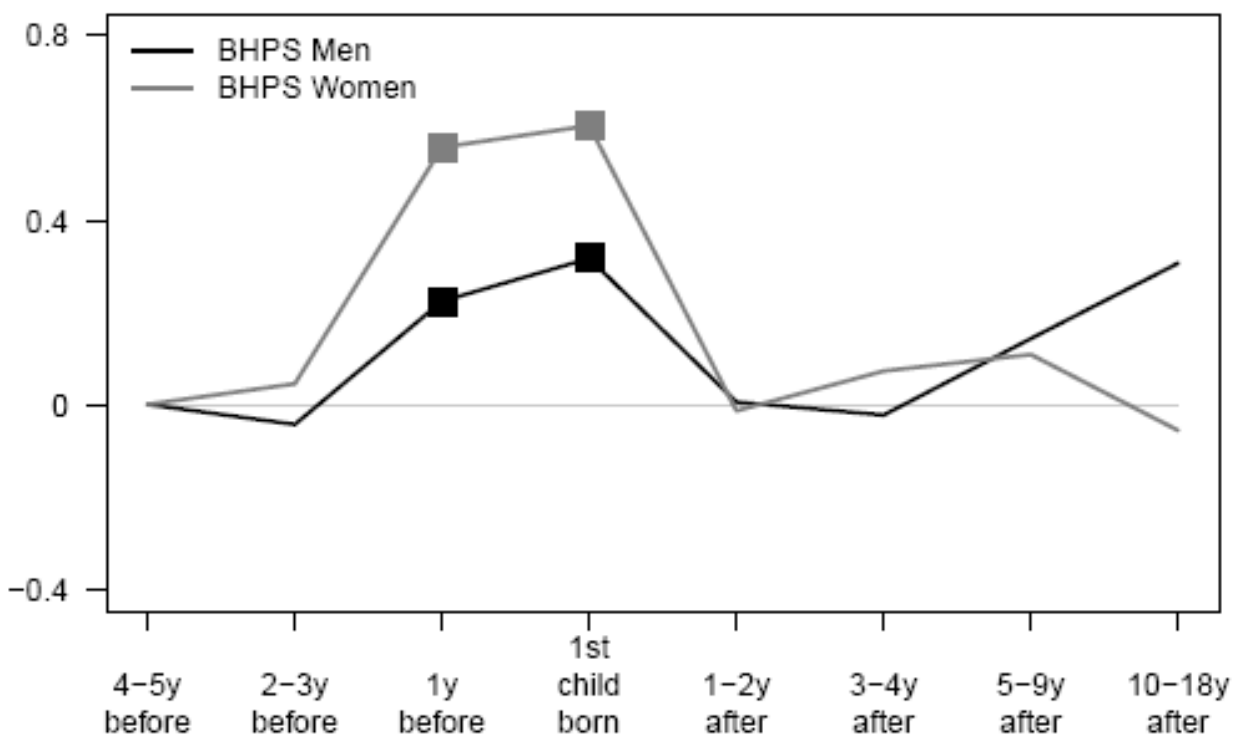

Notes

1. Dots denote significance at .05 level. Shallow dots denote significance at .10 level.

2. The model includes as control variables age and period dummies, and fixed-effects for individuals.

3. Standard errors estimated using robust methods which account for the clustering of data within individuals.

4. For BHPS "10-18y" should be interpreted as " $10-15 y$ " since 14 years is the maximum post-birth follow-up. 
Figure 3A. Happiness trajectory before and after the birth of the first child by age of becoming a parent (ages 15-22, 23-34, 35-49). Fixed-effects linear regressions. SOEP = German Socioeconomic Panel, N=4,513 with 54,976 person years; BHPS = British Household Panel Survey, $\mathrm{N}=2,689$ with 27,307 person years.

\section{SOEP}

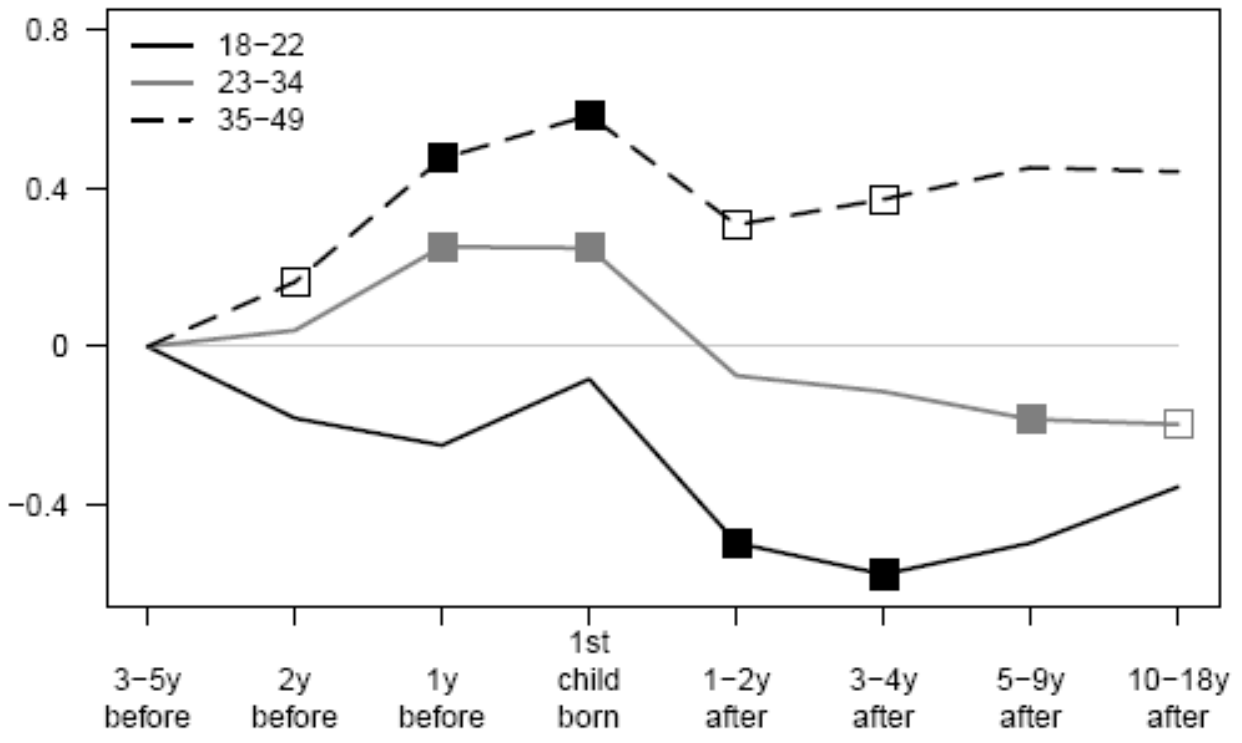

\section{BHPS}

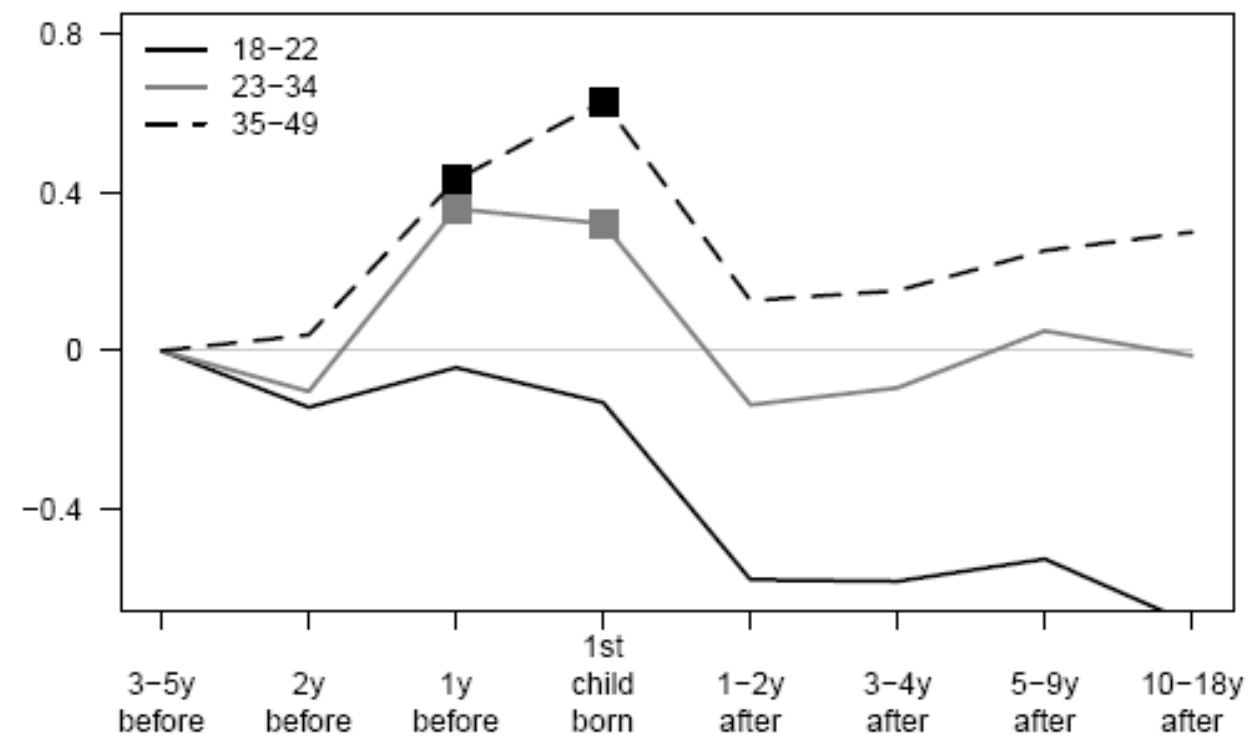

Notes

1. Dots are significant at .05 level. Shallow dots are significant at .10 level.

2. The model includes as control variables age and period dummies, and fixed-effects for individuals.

3. Standard errors estimated using robust methods which account for the clustering of data within individuals.

4. For BHPS "10-18y" should be interpreted as "10-15y" since 14 years is the maximum post-birth follow-up.

5. To get stable estimates for the young parents, in these age-stratified analysis we extend the interval for baseline happiness to cover 3-5 years before birth for all age groups. . 
Figure 3B. Happiness trajectory before and after the birth of the first child by age of becoming a parent and sex. Fixed-effects linear regressions. SOEP = German Socioeconomic Panel, N=4,513 with 54,976 person years.

\section{SOEP: Men}

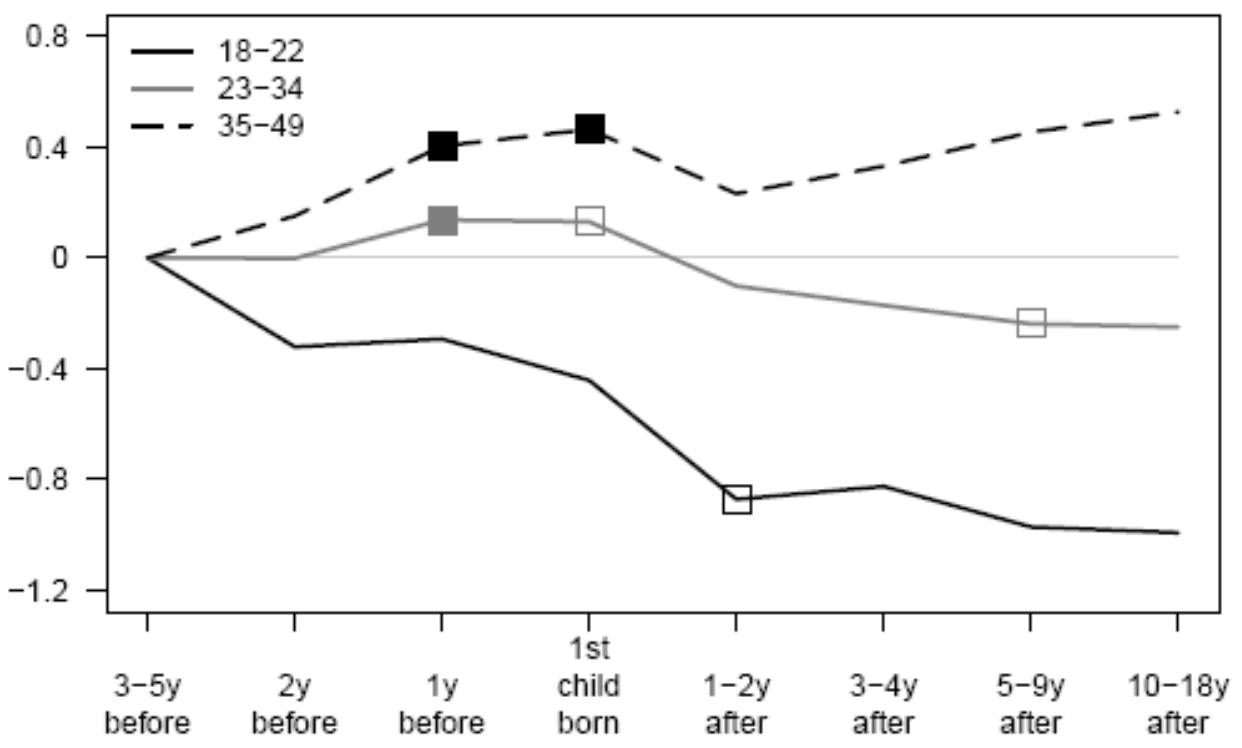

SOEP: Women

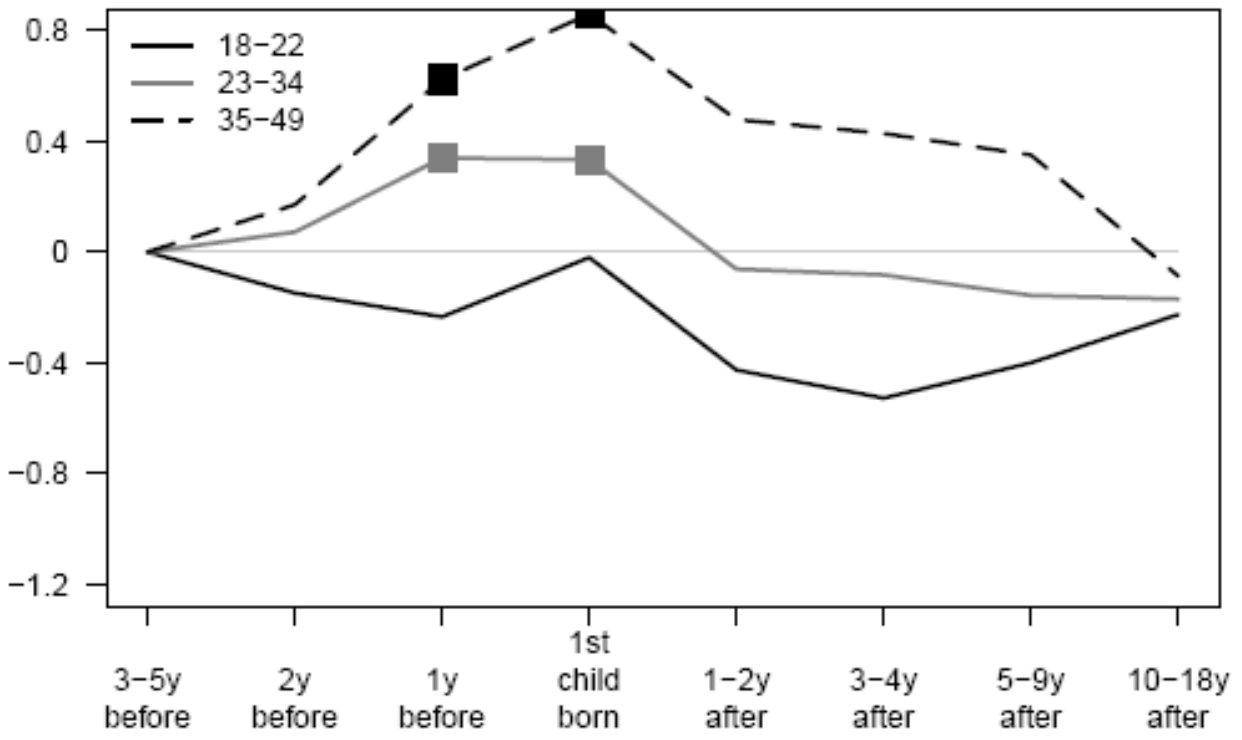

Notes

1. Dots are significant at .05 level. Shallow dots are significant at .10 level.

2. The model includes as control variables age and period dummies, and fixed-effects for individuals.

3. Standard errors estimated using robust methods which account for the clustering of data within individuals.

4. The results are similar for BHPS

5. To get stable estimates for the young parents, in these age-stratified analysis we extend the interval for baseline happiness to cover 3-5 years before birth for all age groups. . 
Figure 4. Happiness trajectory before and after the birth of the first child by marital status. Fixed-effects linear regressions. SOEP = German Socioeconomic Panel, N=4,513 with 54,976 person years; BHPS = British Household Panel Survey, $\mathrm{N}=$ 2,689 with 27,307 person years.

\section{SOEP}

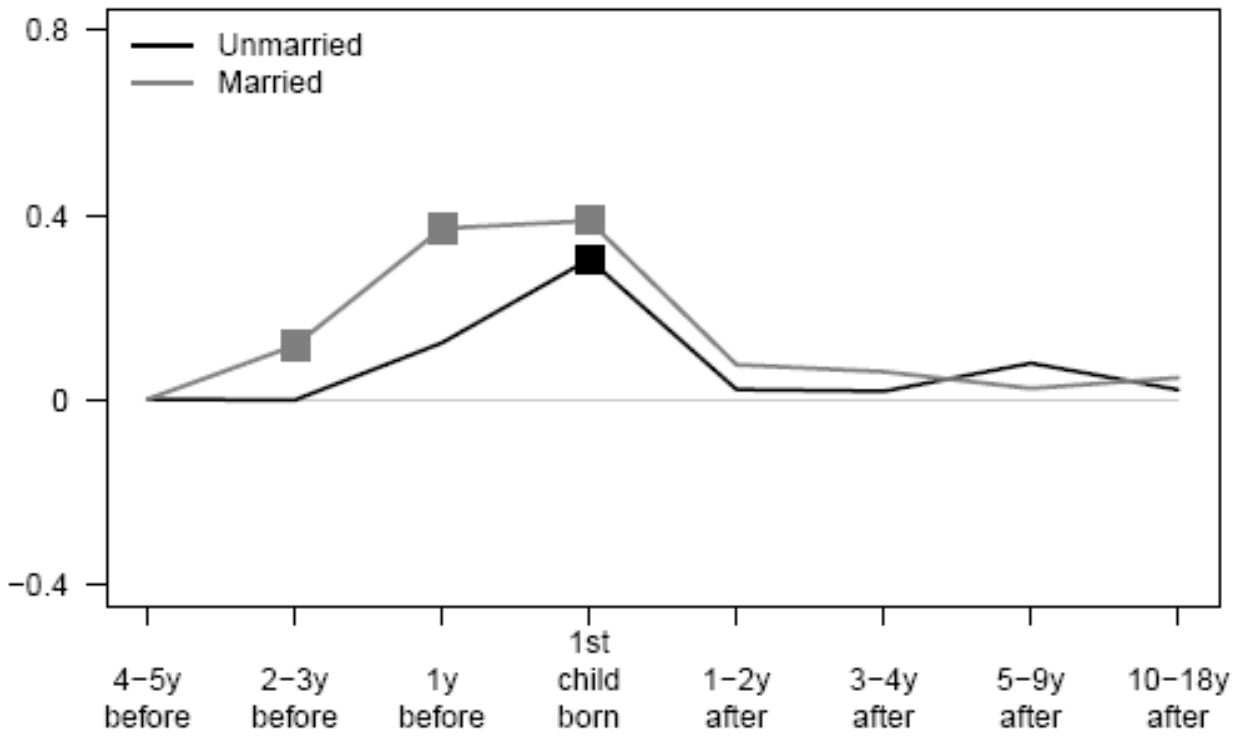

\section{BHPS}

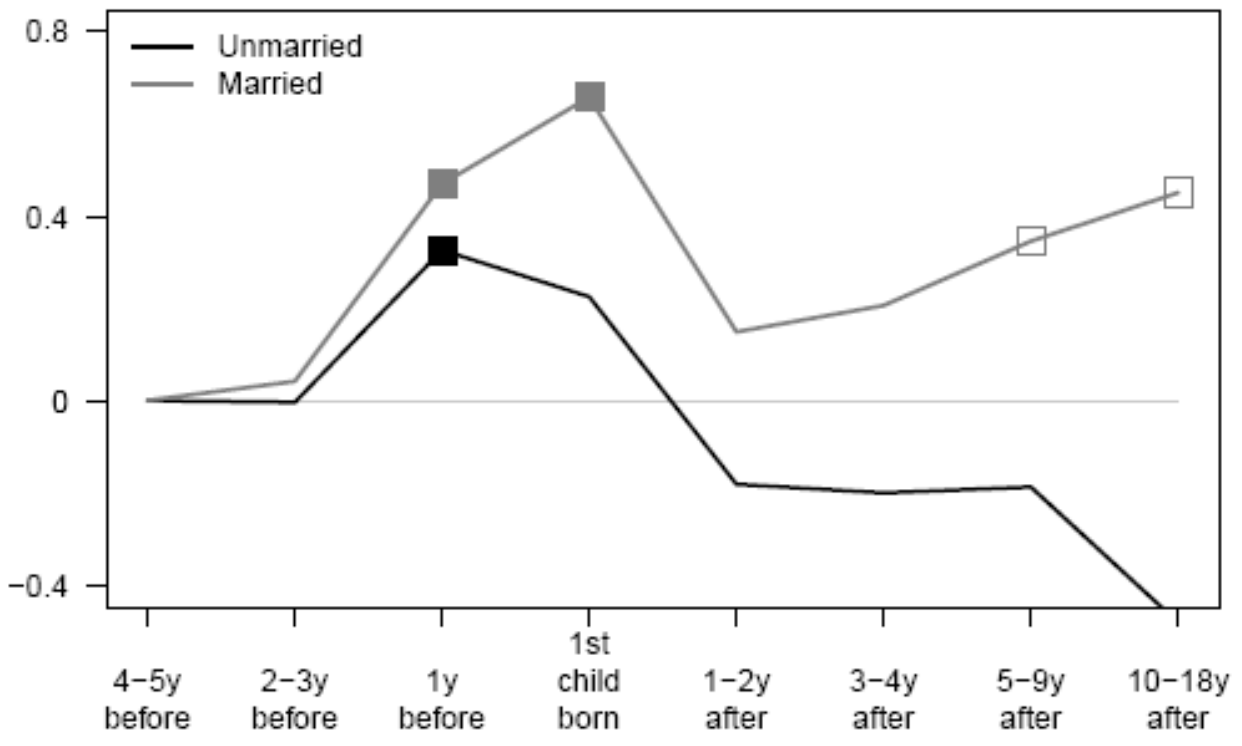

Notes

1. Dots are significant at .05 level. Shallow dots are significant at .10 level.

2. The model includes as control variables age and period dummies, and fixed-effects for individuals.

3. Standard errors estimated using robust methods which account for the clustering of data within individuals.

4. For BHPS "10-18y" should be interpreted as "10-15y" since 14 years is the maximum post-birth follow-up. 
Figure 5. Happiness trajectory before and after the birth of the first child by educational attainment (high $=$ at least 12 years; low = less than 12 years). Fixed-effects linear regressions. SOEP $=$ German Socioeconomic Panel, N=4,513 with 54,976 person years.

\section{SOEP, men}

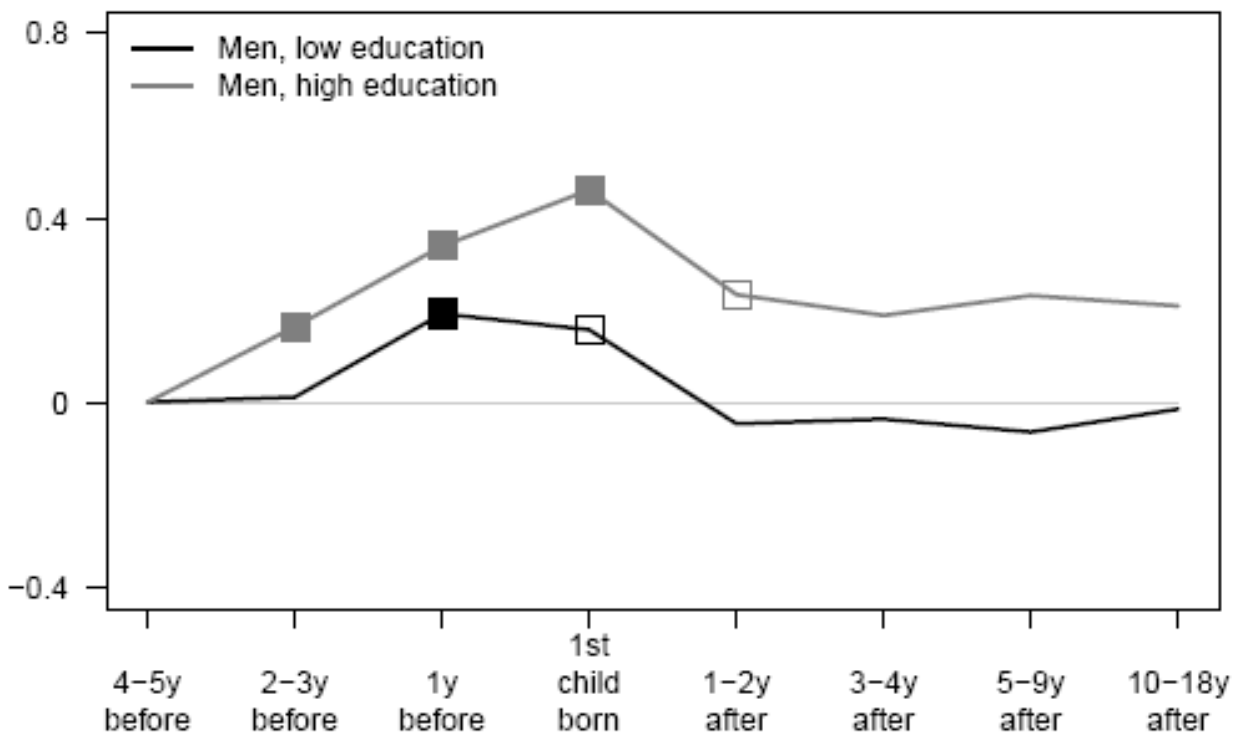

SOEP, women

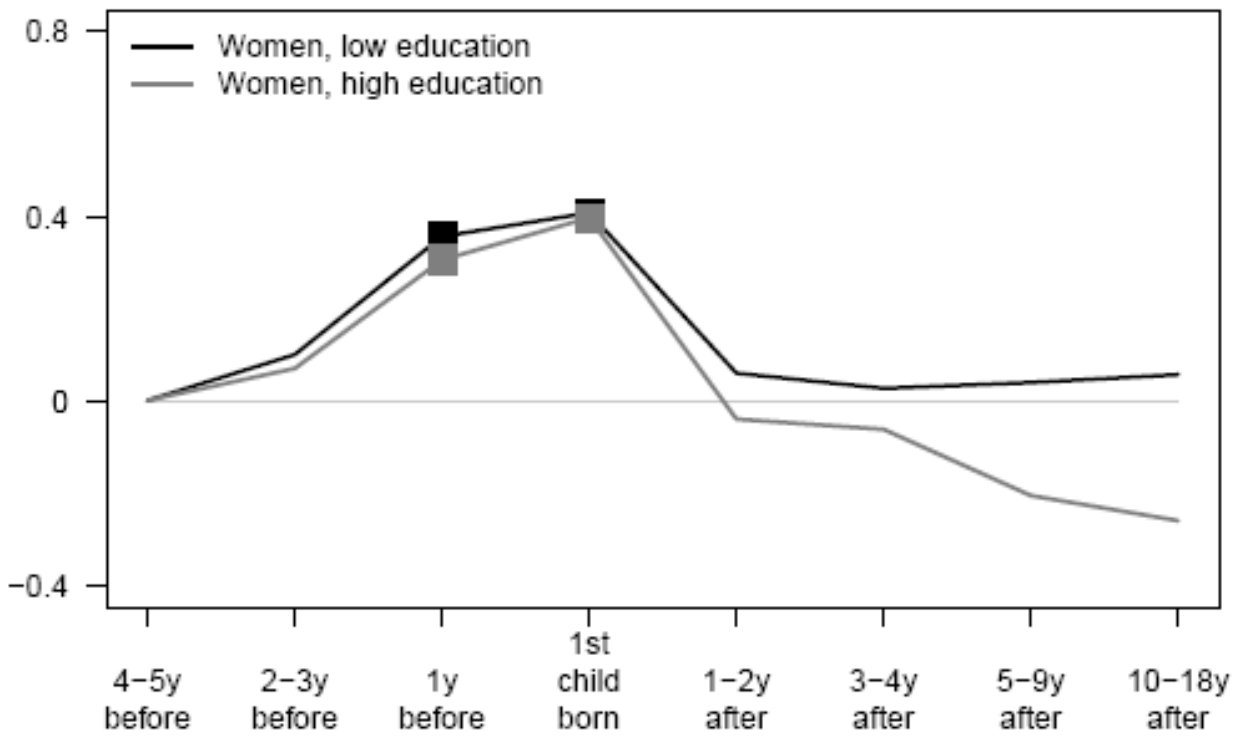

Notes

1. Dots are significant at .05 level. Shallow dots are significant at .10 level.

2. The model includes as control variables age and period dummies, and fixed-effects for individuals.

3. Standard errors estimated using robust methods which account for the clustering of data within individuals. 
Figure 6. Happiness trajectory before and after the birth of a child by birth order. Fixed-effects linear regressions. SOEP $=$ German Socioeconomic Panel, N=4,513 with 54,976 person years.

\section{SOEP: Happiness by parity}

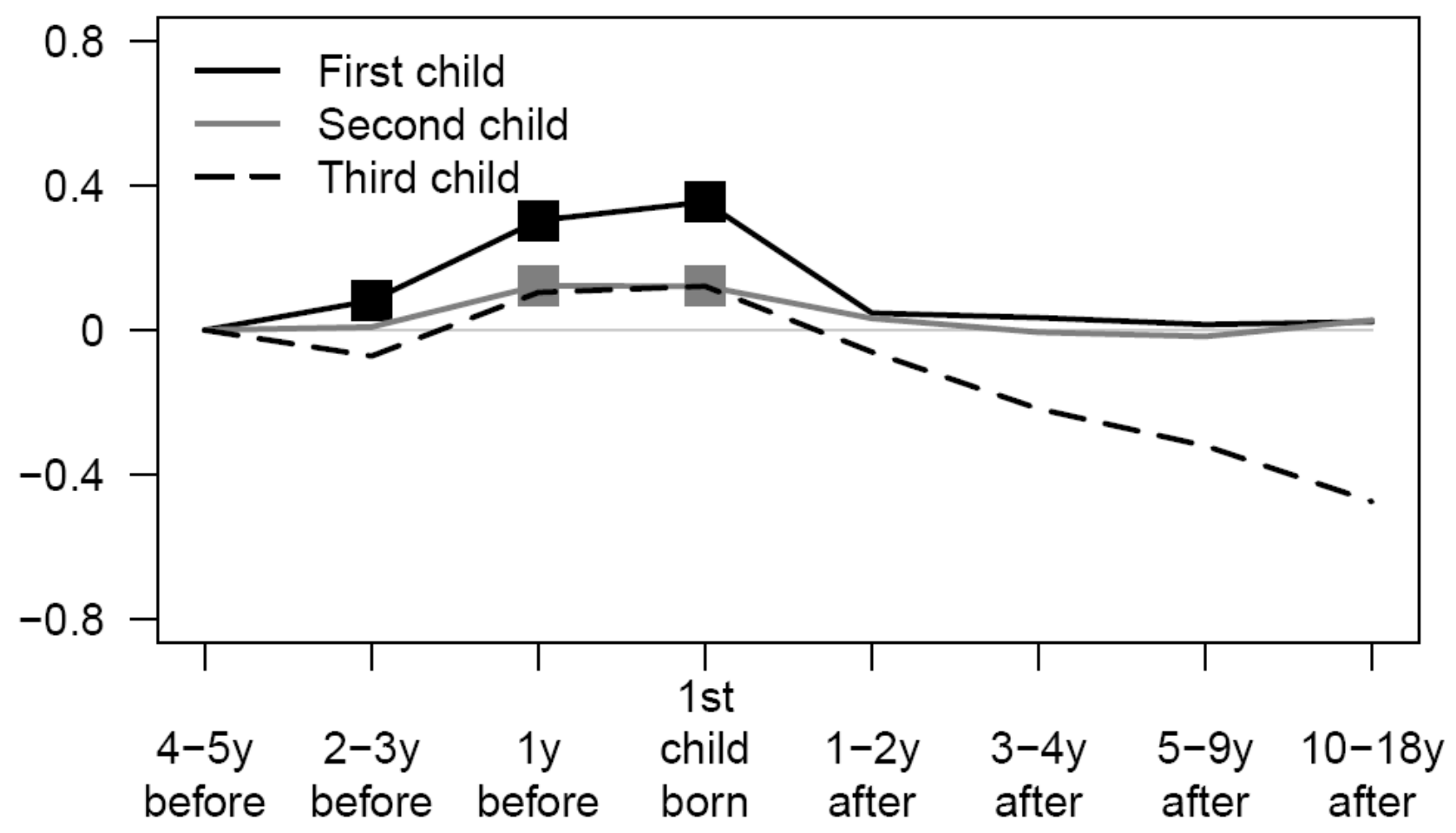

Notes

1. Dots are significant at .05 level. Shallow dots are significant at .10 level.

2. Controls for the previous children's birth and its anticipation, age and period dummies, and fixed-effects.

3. Standard errors estimated using robust methods which account for the clustering of data within individuals.

4. The results are similar for BHPS. 
Figure 7. Happiness trajectory before and after the birth of the first child without time-varying controls (Controls I), with controls for time-varying health, income, marital and labor for status (Controls II), and with Controls II plus controls for the subsequent births (Controls III). Fixedeffects regressions. SOEP $=$ German Socioeconomic Panel, N=4,513 with 54,976 person years .

\section{German Panel SOEP, Men}

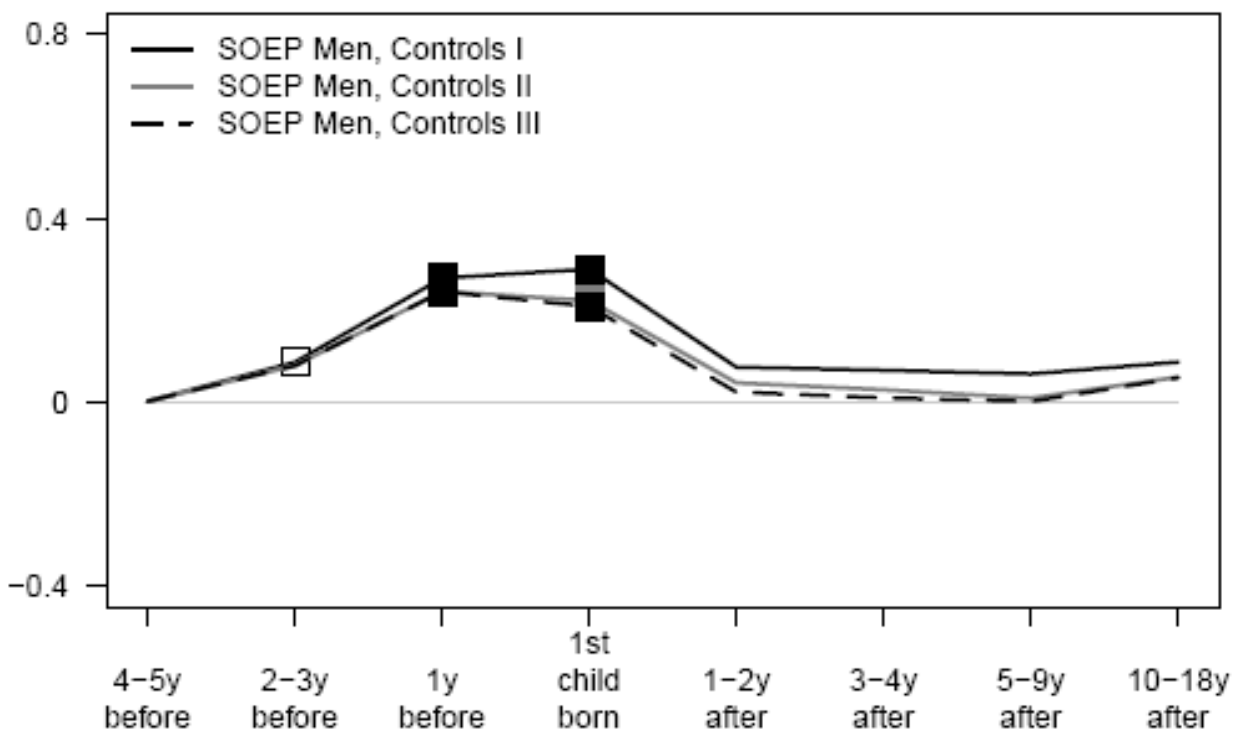

German Panel SOEP, Women

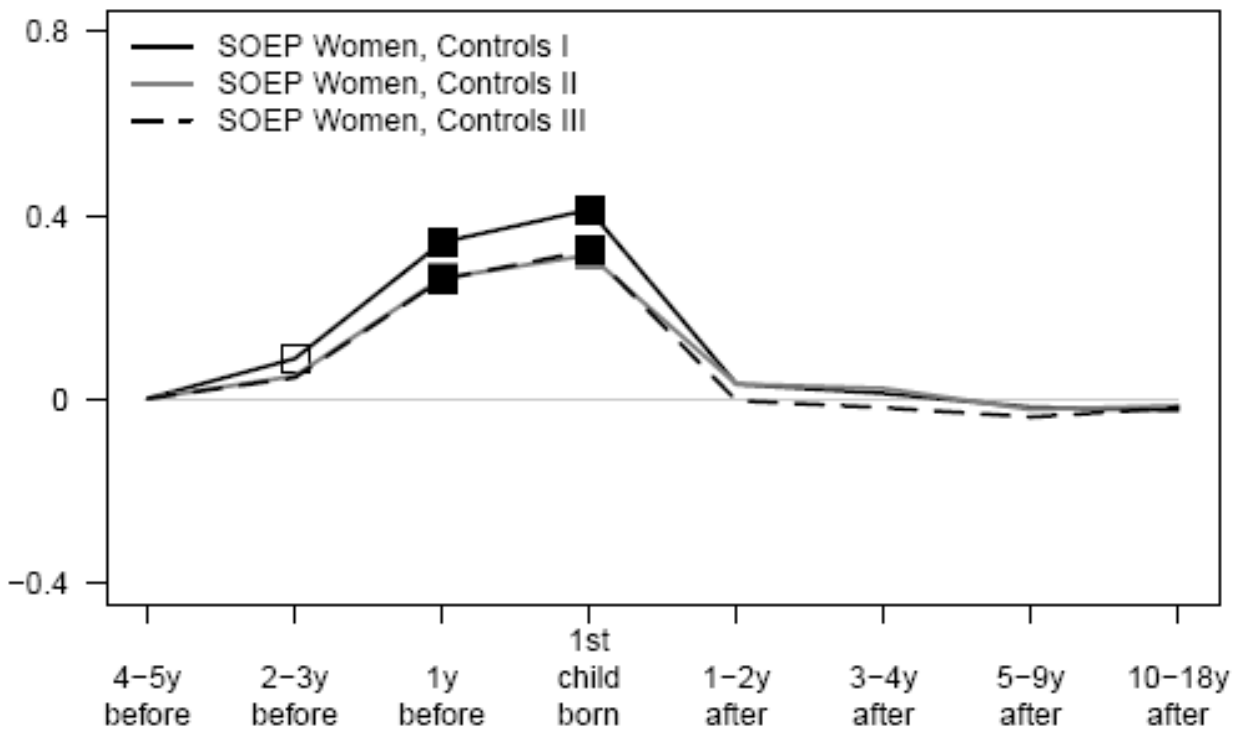

Controls I: No controls for time-varying variables.

Controls II: Controls for time-varying health, income, marital and labor for status

Controls III: Controls II plus controls for second and third births

Notes:

1. Dots are significant at .05 level. Shallow dots are significant at .10 level.

2. The model includes as control variables age and period dummies, and fixed-effects for individuals.

3. Standard errors estimated using robust methods which account for the clustering of data within individuals. The results are similar for BHPS. 